\title{
Review Article \\ Characterization of Inter- and Intramolecular Interactions of Amyloid Fibrils by AFM-Based Single-Molecule Force Spectroscopy
}

\author{
Yinli Li, ${ }^{1,2}$ Hao Liang, ${ }^{1}$ Huiling Zhao, ${ }^{1,2}$ Dong Chen, ${ }^{1}$ Bo Liu, ${ }^{1}$ \\ Thomas Fuhs, ${ }^{2}$ and Mingdong Dong ${ }^{2}$ \\ ${ }^{1}$ Institute of Photo-Biophysics, School of Physics and Electronics, Henan University, Kaifeng, 475004 Henan, China \\ ${ }^{2}$ Interdisciplinary Nanoscience Center (iNANO), Aarhus University, 8000 Aarhus C, Denmark \\ Correspondence should be addressed to Bo Liu; boliu@henu.edu.cn and Mingdong Dong; dong@inano.au.dk
}

Received 1 February 2016; Revised 9 June 2016; Accepted 15 June 2016

Academic Editor: Meiyong Liao

Copyright (c) 2016 Yinli Li et al. This is an open access article distributed under the Creative Commons Attribution License, which permits unrestricted use, distribution, and reproduction in any medium, provided the original work is properly cited.

Amyloids are fibrous protein aggregates defined by shared specific structural features. Abnormal accumulation of amyloid in organs leads to amyloidosis, which results in various neurodegenerative diseases. Atomic force microscopy (AFM) has proven to be an excellent tool investigating amyloids; it has been extensively utilized to characterize its morphology, assembly process, and mechanical properties. This review summarizes studies which applied AFM to detect the inter- and intramolecular interactions of amyloid fibrils and classified the influencing factors of amyloid's nanomechanics in detail. The characteristics of amyloid fibrils driven by inter- and intramolecular interactions, including various morphologies of amyloid fibrils, self-assembly process, and the aggregating pathway, are described. Successful examples where AFM provided abundant information about inter- and intramolecular interactions of amyloid fibrils in different environments are presented. Direct force measurement of intra- or intermolecular interactions utilizing an AFM-based tool, single-molecular force spectroscopy (SMFS), is introduced. Some mechanical information such as elasticity, adhesiveness, and strength was obtained by stretching amyloid fibrils. This review helps researchers in understanding the mechanism of amyloidogenesis and exploring the properties of amyloid using AFM techniques.

\section{Introduction}

Improper aggregation of polypeptide fragments may result in various neurological disorder diseases [1], such as Alzheimer's disease (A $\beta$ aggregation) [2-5], Parkinson's disease [6], Huntington's disease (Huntington aggregation) [7, 8], prion disease (PrP aggregation) [9], and amyotrophic lateral sclerosis (ALS) [10]. Amyloid aggregations are also found in type II diabetes (islet amyloid polypeptide) [11-14] and dialysis related amyloidosis ( $\beta-2$ microglobulin aggregation) [6]. Recently, more and more studies have suggested that these diseases are related to the aggregations formed by amyloids sharing specific structural traits. Single soluble amyloid proteins start to interact with each other, and these intermolecular interactions finally assemble the soluble amyloid into various insoluble forms. In addition, a great variety of heterogeneous morphologies detected in self-assembly processes indicate different assembly pathways of amyloid fibrils [1517]. As a whole, their assembly pathways can be simply described as soluble protein $\rightarrow$ nucleation $\rightarrow$ fibrillar elongation/lateral aggregation $\rightarrow$ mature network [18]. Though multiple amyloids have been widely explored in recent years, their pathogenic mechanism has not been elucidated clearly.

Atomic force microscopy (AFM) is an excellent tool which has been used extensively to study the fibrillar ultrastructures. AFM enables us to clearly visualize individual biological macromolecules at the nanometer scale [19-23]. Time-lapse AFM imaging [24] has been successfully adopted to monitor the growth of individual peptide fibrils and to characterize the influence of the chemical environment on amyloid aggregation [25]. AFM-based single-molecule force spectroscopy (SMFS) [26] has made force measurement at the single-molecule level with pico-Newton $(\mathrm{pN})$ force resolution possible. This technique enables researchers to analyze 


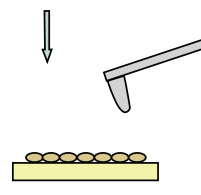

(1)

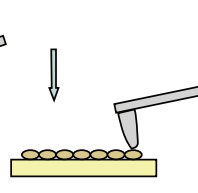

(2)

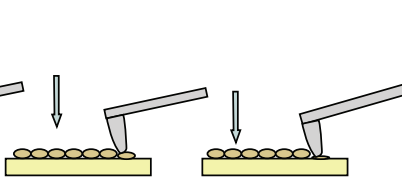

(3)

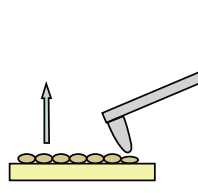

(5)

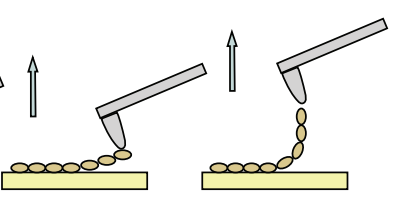

(6)

(7)

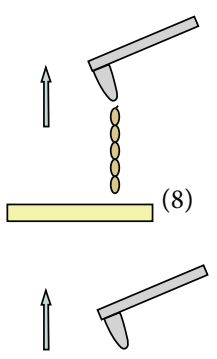

(a)

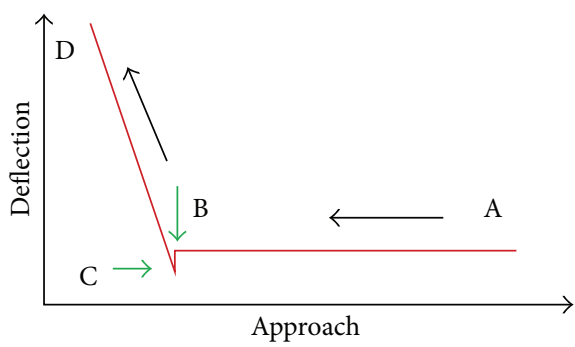

(b)

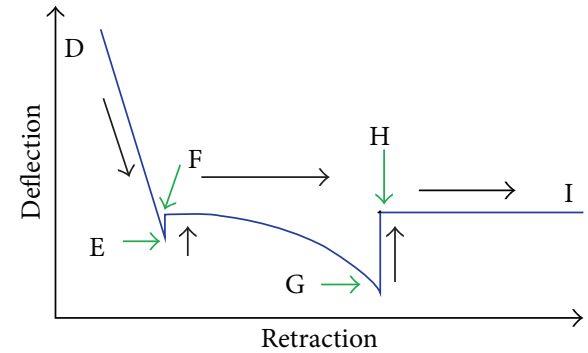

(c)

FiguRE 1: (a) Schematic principle of single-molecular force microscopy, (b) approaching force curve, and (c) retracting force curve. In the schematic of Figure (a), (1)-(4) show the approaching progress. (1) AFM tip moves forward to sample. (2) AFM tip contacts sample surface. (3) AFM tip indents sample. (4) AFM tip reaches the defined deflection value; (6)-(9) show the retracting progress, molecules firstly adsorb on AFM tip and then are gradually pulled away from substrate and finally rupture from substrate or from AFM tip.

inter- and intramolecular interactions [27, 28]. The obtained mechanical fingerprint [29] of amyloid fibrils has proven that SMFS is an efficient tool to explore the mechanisms of amyloid assembly process, the differences of various amyloids, and the mechanisms of interactions with chemicals and chaperones.

We review AFM techniques applied to characterize and understand the assembly process of amyloid fibrils involved in pathogenic disorders. We summarized AFM studies of amyloid fibrillogenesis focusing on the morphology, kinetics, and models of amyloid self-assembly. The investigation of the inter- or intramolecular interaction of amyloid fibrils using AFM-based SMFS was reviewed to explore the assembly mechanism and mechanical properties of various shaped fibrils, such as globular oligomers, protofibrils, mature intertwined fibrils, and network structures.

\section{Principle of AFM-Based SMFS}

AFM is a type of Scanning Probe Microscope (SPM) [65] with high-resolution, and now it has become one of the foremost tools in imaging, measuring, and manipulating matter at nanoscale [66-69]. AFM allows imaging both in ambient and in liquid environments which is of great importance for biological molecules [70-73]. AFM-based SMFS stands out among various single-molecule techniques [74-77] because of its high detection rate, easy operation, and wide application in measuring weak inter- or intramolecule interactions [7880]. Through SMFS technique, multiple properties, such as elasticity and viscosity [81], can be analyzed in detail. At the same time, SMFS is analytic technique applied not only to measure mechanical properties of various proteins but also to manipulate single-molecule at pico-Newton scale [78], for example, probing the helical structure, unfolding $\beta$-fold structure [64], and measuring intermolecular interactions.

Compared with simple topographic characterization, the AFM-based single-molecule force spectroscopy is more complex [26]. SMFS measurement is based on full knowledge of the force on the tip during approach and retraction. During the approach, the AFM tip moves slowly toward the sample surface and the cantilever is bent toward the sample surface when the tip-sample distance arrives at a certain forcedistance, as it starts to feel long-range attractive forces like van der Waals forces (Figures 1(a), (1)-(2), and 1(b), A-B). With further movement, the cantilever starts to feel repulsive forces as well; it eventually recovers equilibrium. Further approach to the sample increases the repulsive force that will bend the cantilever away from the sample, and the tip finally stops at the predefined force value (Figure 1(a), (4)-(5)). The compressive stiffness or elasticity modulus of the molecule can be deduced from the force-distance curve between C and D from this approaching process. During retraction the probe slowly moves away from the substrate and fingerprint information representing the molecular mechanical properties is captured during the stretch-relaxation process. In the retraction force curve (Figure 1(c)), point E represents an adhesion force caused by nonspecific interaction between the AFM tip and substrate. Point F indicates the start of the phase when 
the molecule is pulled away from the substrate. The force increases until point $G$ when the molecule ruptures from the AFM tip or substrate, and cantilever returns to the equilibrium position (point $\mathrm{H}$ ). The nanomechanics such as the stretching or unzipping response of the molecule can be obtained from this pulling process.

The mechanical responses observed in SMFS can be divided into three categories: single nonlinear elastic curve, saw-tooth curve, and irregular mechanical event [64, 82]. The long single nonlinear elastic curve is characterized by a large peak which indicates the detachment of the sample from the tip. Some groups reported that peaks in the force plateau [82] were caused by simultaneous unzipping of the molecular strand. The saw-tooth force curve is composed of several peaks starting with irregular peaks and ending with a rupture force. Each peak represents an unfolding or sudden detachment event. The plateau force curve has a long uniform plateau and an abrupt force drop belongs to the manipulating response of $\beta$-sheet [64]. An irregular mechanical event generally refers to complex multimolecular interactions [83] in which interconnected fibrils are stretched sequentially leading to the extension and breaking of loops or bonds in one pulling cycle. Among the mechanical responses, single nonlinear and orderly force patterns are useful in exploring mechanical properties. At the same time two prominent theoretical models, the Freely-Jointed Chain (FJC) model [84] and the Worm-Like Chain (WLC) model [85], have been developed to analyze these SMFS data.

\section{Intermolecular Interaction}

The assembly of amyloid peptides is a dynamic process. The pathway from soluble molecules to insoluble fibrils is driven by intermolecular interactions which usually result in the formation of heterogeneous shaped structures. Amyloid fibrils interact with each other and aggregate into larger fibrils and eventually transform into texture structures. According to previous reports, the textured structures are constituted by different mature fibrils generated through multiple pathways. Therefore, obtaining the morphologies of various structures at different stages is essential to comprehend their assembly process.

3.1. Self-Assembled Structures. Plenty of shapes of amyloid structures were reported in many previous studies, including globular, $\beta$-hairpin, $\beta$-sheet, disk-like, worm-like, rod-like, honeycomb, parallel, and braided structures [1]. The variety of these assembled structures is attributed to the intermolecular interactions including hydrogen bonds, electrostatic interaction, and hydrophobic interactions [32, 38, 86-89]. The globular structures formed at the beginning of the incubation process are easily observed in AFM (Figure 2(a)). They consist of many monomers as well as disk-like structures $[16,39,44$, 58]. Branch-like [14] and parallel structures [38] (Figures 2(b) and 2(c)) are the intermediate products [90] composed of several oligomers. A mature fibrillar structure (Figure 2(d)) is a large fibril composed of two or more fibrils. Table 1 shows the dimensions of fibrillar structures obtained at different incubation stages, and the stages are represented by their typical structures.

McAllister et al. [87] found that the increase of proteinprotein interaction usually resulted in morphological transformations, for example, $\beta$-sheet conformation with an elevated content. Gerber et al. [91] have reported disk-like structures that form stacks through interoligomer interactions. Sandal et al. [64] have studied $\beta$-like formation of $\alpha$-Syn and found the relative abundance of the $\beta$-like structures significantly increased in different conditions promoting the aggregation of $\alpha$-Syn, such as pathogenic A30P mutation and high ionic strength buffer. Sibley et al. [86] found that the interaction between insulin and porphyrin gave rise to circular, ring-like structures as well as fibrils. The possible reason to form various morphologies is related to the interactions between specific residues. Jansen et al. [38] found that the compact character or mature fibrillar structures might originate from the effort to minimize the exposure of hydrophobic residues. In order to explore the effects of specific residues, some functional residues were substituted during AFMbased measurements. Various mutations showed distinctive functions: some were prone to form amyloid fibrils while others formed spherical aggregates; some functioned as a $\beta$-sheet breaker while others were promoting overall-length aggregation [32, 92-94]. For example, $\mathrm{A} \beta_{40}$ and $\mathrm{A} \beta_{25-35}$ were found to form small oligomers and thin fibrils, respectively [94]. However, A53T and A30P mutants of $\alpha$-Syn were found to form spherical or annular protofibrillar structures [34]. Common morphologies were observed for some residues, for example, twisted fibrils derived from the Q24K mutant, and spherical aggregates and short fibrils derive from other mutants. E46K mutant displays a very distinctive smaller periodicity [36] compared with other mutants. We summarize the different shapes of amyloid with different dimensions in Table 1.

3.2. Assembly Processes. Time-lapse monitoring of the amyloid aggregation process is crucial to deepen the understanding of the amyloid aggregation mechanisms. The assembly of various amyloid fibrils can be followed by in situ time-lapse AFM images. Amyloid aggregation is commonly divided into two stages: nucleation stage and fibril growth stage [47].

In the nucleation stage, often called lag-phase, it is critical to understand the behavior of "seed-like" structures and intermediate prefibrillar structures, as these are the starting point of the overall self-assembly process [95, 96]. Fukuma revealed that the lag-phase was related to the increase of the mass concentration of elongated fibrils, and long incubating time was not an important factor during the nucleation stage $[38,97]$. When studying on the process of $\mathrm{A} \beta$ aggregation, Harper et al. [98] found that the rate of oligomers was slower than that of fibrils and that fibrils rapidly aggregated once sufficient nucleated oligomers formed. Their results indicated that the elongation rate of individual amylin protofibrils was $1.1 \pm 0.5 \mathrm{~nm} / \mathrm{min}$. In line with the aggregation pathway, the stability of monomer and oligomer state was significantly lower than that of the following stages. It is reported that the inhibition of fibril formation could be realized by reducing the stability of protofibrils, by blocking protofibril-protofibril 
TABLE 1: Dimension of different shapes for various amyloid fibrils based on molecular interaction.

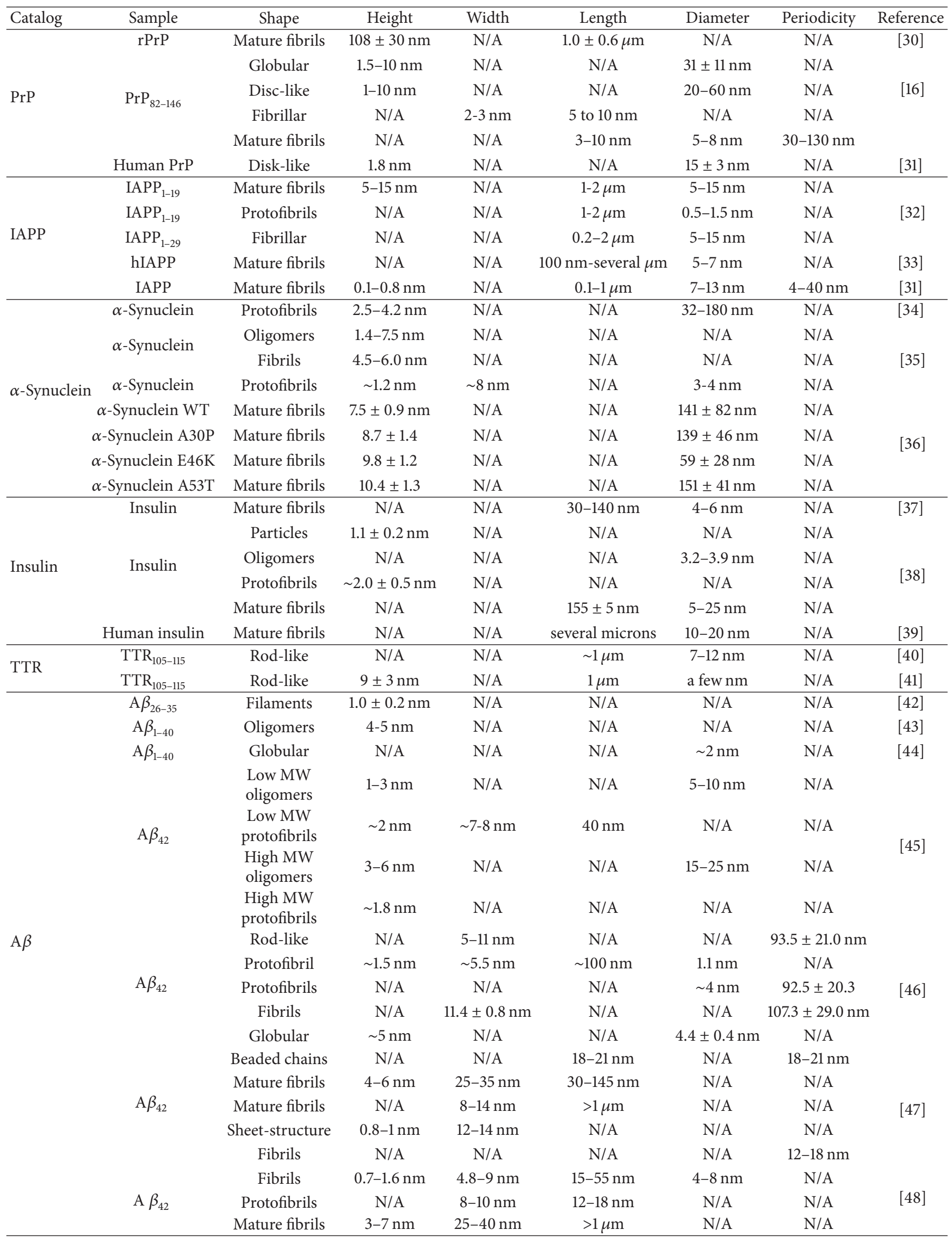


TABle 1: Continued.

\begin{tabular}{|c|c|c|c|c|c|c|c|c|}
\hline Catalog & Sample & Shape & Height & Width & Length & Diameter & Periodicity & Reference \\
\hline \multirow{11}{*}{$\beta$-lactoglobulin } & \multirow{5}{*}{$\beta$-lactoglobulin } & Worm-like & $2.7 \pm 0.5 \mathrm{~nm}$ & $\sim 7 \mathrm{~nm}$ & $100-500 \mathrm{~nm}$ & N/A & N/A & \multirow{5}{*}[49]{} \\
\hline & & Protofibrils & $1.2 \pm 0.4 \mathrm{~nm}$ & $\sim 7 \mathrm{~nm}$ & $>1 \mu \mathrm{m}$ & $8 \pm 2 \mathrm{~nm}$ & $53 \pm 8 \mathrm{~nm}$ & \\
\hline & & particles & $3.8 \pm 0.6 \mathrm{~nm}$ & N/A & $\sim 200 \mathrm{~nm}$ & $8 \pm 2 \mathrm{~nm}$ & N/A & \\
\hline & & Oligomers & $2-8 \mathrm{~nm}$ & N/A & N/A & $35-70 \mathrm{~nm}$ & N/A & \\
\hline & & Mature fibrils & N/A & $15-20 \mathrm{~nm}$ & N/A & N/A & $60-100 \mathrm{~nm}$ & \\
\hline & \multirow[t]{2}{*}{$\beta$-lactoglobulin } & Mature fibrils & $2-3 \mathrm{~nm}$ & N/A & $>10 \mu \mathrm{m}$ & N/A & $30-40 \mathrm{~nm}$ & \multirow[t]{2}{*}[50]{} \\
\hline & & Mature fibrils & N/A & $8.5 \pm 1.4 \mathrm{~nm}$ & $0.1-2 \mu \mathrm{m}$ & N/A & $34.3 \pm 7.4 \mathrm{~nm}$ & \\
\hline & \multirow{4}{*}{$\beta$-lactoglobulin } & Worm-like & $1.1 \pm 0.3 \mathrm{~nm}$ & $7.1 \pm 1.6 \mathrm{~nm}$ & $150-500 \mathrm{~nm}$ & N/A & $\mathrm{N} / \mathrm{A}$ & \multirow{4}{*}[51]{} \\
\hline & & Protofibrils & $0.9 \pm 0.2 \mathrm{~nm}$ & $2.5-4 \mathrm{~nm}$ & N/A & N/A & N/A & \\
\hline & & Oligomers & $1.8 \pm 0.4 \mathrm{~nm}$ & N/A & N/A & $\sim 3.6 \mathrm{~nm}$ & N/A & \\
\hline & & Protofibril & $1.4 \pm 0.3 \mathrm{~nm}$ & $\sim 5 \mathrm{~nm}$ & N/A & $8 \mathrm{~nm}$ & N/A & \\
\hline \multirow{8}{*}{$\beta 2$-microglobulin } & \multirow{4}{*}{$\beta 2$-microglobulin } & Worm-like & $\sim 3.5 \mathrm{~nm}$ & N/A & $\sim 150-160 \mathrm{~nm}$ & N/A & N/A & \multirow{4}{*}[52]{} \\
\hline & & Rod-like & $\sim 3.5 \mathrm{~nm}$ & N/A & $\sim 20-150 \mathrm{~nm}$ & N/A & N/A & \\
\hline & & Protofibril & $4-5 \mathrm{~nm}$ & N/A & $>1000 \mathrm{~nm}$ & N/A & N/A & \\
\hline & & Mature fibrils & $5-8 \mathrm{~nm}$ & N/A & N/A & N/A & $30-100 \mathrm{~nm}$ & \\
\hline & \multirow{4}{*}{$\beta 2$-microglobulin } & Mature fibrils & $4-9 \mathrm{~nm}$ & $100-500 \mathrm{~nm}$ & N/A & N/A & N/A & \multirow{4}{*}[53]{} \\
\hline & & Protofibril & $4 \pm 1 \mathrm{~nm}$ & $17 \pm 3 \mathrm{~nm}$ & $\mathrm{~N} / \mathrm{A}$ & N/A & $25-60 \mathrm{~nm}$ & \\
\hline & & Protofibrils & $2.2 \pm 0.5 \mathrm{~nm}$ & $18 \pm 1 \mathrm{~nm}$ & N/A & N/A & $20-30 \mathrm{~nm}$ & \\
\hline & & Oligomers & N/A & N/A & N/A & $10-12 \mathrm{~nm}$ & N/A & \\
\hline \multirow{4}{*}{ EAK } & \multirow{4}{*}{ EAK16 } & $\begin{array}{l}\text { EAK16-IV } \\
\text { globular }\end{array}$ & $2-3.2 \mathrm{~nm}$ & N/A & N/A & $34 \mathrm{~nm}$ & N/A & \multirow{4}{*}[54]{} \\
\hline & & $\begin{array}{l}\text { EAK16-IV } \\
\text { fibrillar }\end{array}$ & $0.4-3.7 \mathrm{~nm}$ & $28.69 \pm 2.27 \mathrm{~nm}$ & N/A & $60 \mathrm{~nm}$ & N/A & \\
\hline & & $\begin{array}{l}\text { EAK16-II } \\
\text { fibrillar }\end{array}$ & $0.3-2.2 \mathrm{~nm}$ & $12-40 \mathrm{~nm}$ & N/A & N/A & N/A & \\
\hline & & $\begin{array}{l}\text { EAK16-II } \\
\text { globular }\end{array}$ & N/A & N/A & N/A & $48 \mathrm{~nm}$ & N/A & \\
\hline \multirow{2}{*}{ Ceratoplatanin } & \multirow{2}{*}{ Ceratoplatanin } & Protruding & $50-60 \mathrm{~nm}$ & N/A & N/A & N/A & N/A & \multirow{2}{*}[17]{} \\
\hline & & Rod-like & $6-8 \mathrm{~nm}$ & N/A & N/A & N/A & N/A & \\
\hline \multirow{2}{*}{ SSP } & SSP1 & Mature fibrils & $6.0 \mathrm{~nm}$ & $6.4 \pm 0.2 \mathrm{~nm}$ & $\mathrm{~N} / \mathrm{A}$ & $6.4 \mathrm{~nm}$ & N/A & \multirow{2}{*}[55]{} \\
\hline & SSP2 & Mature fibrils & $2.5 \mathrm{~nm}$ & $6.2 \pm 0.3 \mathrm{~nm}$ & N/A & $6.2 \mathrm{~nm}$ & N/A & \\
\hline \multirow{3}{*}{ Glucagon } & \multirow{3}{*}{ Glucagon } & Mature fibrils & $0.1-1 \mu \mathrm{m}$ & N/A & $15 \mu \mathrm{m}$ & $52-55 \mathrm{~nm}$ & N/A & \multirow{3}{*}[56]{} \\
\hline & & Disc-like & $1.5 \pm 0.5 \mathrm{~nm}$ & $20.8 \pm 5.2 \mathrm{~nm}$ & N/A & N/A & N/A & \\
\hline & & Protofibrils & $6.05 \mathrm{~nm}$ & $32.9 \mathrm{~nm}$ & N/A & N/A & N/A & \\
\hline
\end{tabular}

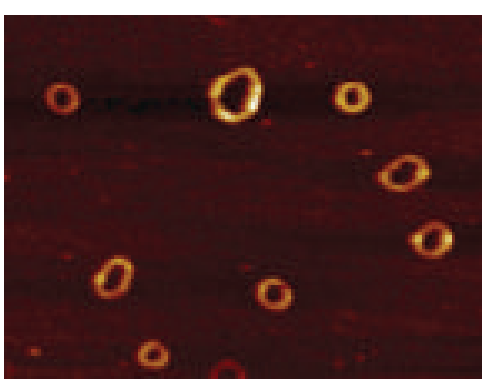

(a)

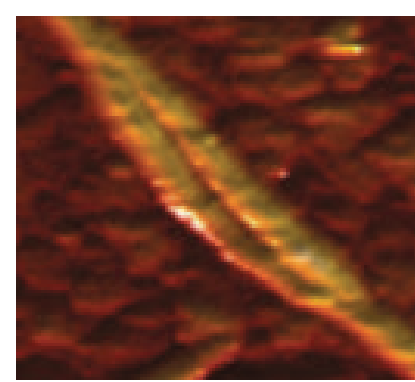

(b)

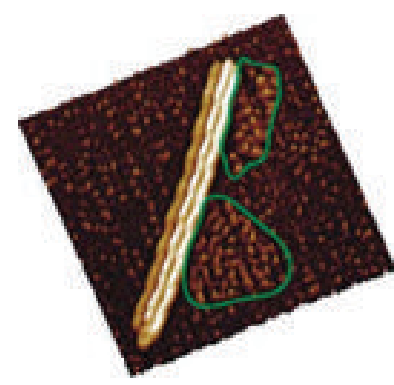

(c)

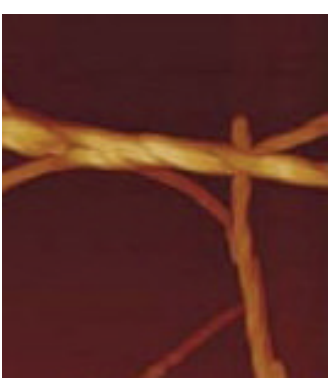

(d)

FIGURE 2: Distinctive shapes of various amyloid fibrils. (a) globular and disk-like structures [14], (b) branch-like structures [14], (c) parallel tubular fibers of insulin [38], and (d) mature insulin fibrils [38]. (Figures 2(a), 2(b), 2(c), and 2(d) are parts of figures from reference.)

interaction or by shifting the protofibril-monomer equilibrium. Oligomers contain nonfibrillar $\beta$-structures, and their total amount remains almost constant from the second half of the nucleation phase to the end of the aggregation process [44].
In the fibril growth stage, growth rate and aggregation propensity of amyloid assembly are influenced by different sequences or specific residues of the peptide. The corresponding amyloid assembly has been investigated by substitution of residues. Various amyloid peptides and their mutants were 
studied, such as $\mathrm{A} \beta$ with mutant $\mathrm{A} \beta \mathrm{E} 22 \mathrm{G}, \mathrm{A} \beta_{25-35+\mathrm{N} 27}$, or $\mathrm{A} \beta_{40}$ ARC $[59,99,100], \alpha$-synuclein with disease-related A30P, E46K, and A53T variants [34, 36, 93, 101, 102], mutant huntingtin (Htt) $[103,104]$, PAPBN1 N-WT with N-(+7)Ala mutant [105], and $\beta 2$-microglobulin with its deamidated variant N17D [106]. Another example, rat amylin, although $84 \%$ residues are the same as in human amylin, cannot form amyloid fibrils [107]. The possible reason is that those residues, which differ from human amylin, influence the peptide assembly $[59,94]$. In $A \beta$ mutation $(A \beta E 22 G)$, fibrillization process will be accelerated, while the abundance of nonfibrillar assemblies will be decreased. Conway et al. [101] reported that the fibrillation rate of specific mutant peptides or mutant mixtures was faster than that of WT peptide. Seed-induced fibrillation of N-WT of PAPBN1 was slower than that of $\mathrm{N}-(+7)$ Ala. Monitoring the solubilization kinetics, they found that the stability of N-WT and N-(+7)Ala fibrils was different. In another case [98], $\mathrm{A} \beta_{1-40}$ and $\mathrm{A} \beta_{1-42}$ formed two discrete morphologies, and $\mathrm{A} \beta_{1-42}$ aggregates grew faster than $A \beta_{1-40}$ ones. However, the rate of $A \beta$ amyloid aggregation in vitro was limited by the amount of available $\mathrm{A} \beta$ nuclei. Moreover, the amounts of aggregated $\mathrm{A} \beta_{1-40}$ and A $\beta_{1-42}$ protofibrils obviously differed from each other. Marek et al. [92] suggested that the difference between the amount of aggregated $\mathrm{A} \beta 1-40$ and $\mathrm{A} \beta 1-42$ protofibrils was caused by different residues affecting the aggregating rate of fibrillogenesis. In their study, the kinetics of amyloid assembly and the resulting morphology were influenced by the aromatic residues, which were important during the lag-phase in AFM measurements. Table 2 shows the assembly parameters of various amyloids under distinctive incubating environments. This overview suggests that experimental factors, such as buffer, $\mathrm{pH}$, temperature, and concentration, are critical to the result of the fibrillation process.

3.3. Assembly Pathways. The aggregation process was reported to be associated with the pathology of the corresponding amyloid protofibrils. Numerous studies have been carried out to explore the aggregation pathway [13, 108]. For the mechanism of amyloid fibrillogenesis, several explanations have been established. It is suggested that the common noncovalent structure of proteins such as backbone hydrogen bonding and hydrophobic interaction [17] were the main forces driving the amyloid fibrils' aggregation. In early studies, a mechanism of nucleated conformational conversion, so-called on-pathway, was applied to explain the amyloid aggregation. However, exceptions have been found. Therefore, an alternative off-pathway mechanism was proposed to explain fibrillogenesis $[57,63]$. While more and more studies explore the mechanism of amyloid aggregation, models for various kinds of amyloid fibrils have been designed to explain the amyloidogenesis formation. Here, we propose a model (Figure 3) based on various previous studies $[15-17,34,38,46,53,56,62,63,109-113]$ to elucidate the mechanism of multipathway aggregation and describe it in detail in the following parts.

3.3.1. Nucleation and Elongation. AFM measurements revealed that the most favorable nucleation pathway contains a two-stage sequential conversion (Figure 3, steps 1 and 2), in which soluble monomers are aggregated into small annular and spheroidal mature oligomers $[14,114]$ and then these seeds grow by further addition of more mature monomers. Mature oligomers have accumulated more monomers but still show globular morphology. Oligomers still have spherical superstructure but already show characteristic amyloid folding [93]. $\mathrm{A} \beta_{1-42}[45,47,48,115,116]$, glucagon $[56,117]$, amylin $[24,107]$, and $\beta$-lactoglobulin $[49,50]$ have been observed to aggregate through the nucleation pathway. Fibril elongation (Figure 3, steps 4, 5, and 6) becomes the main process once a critical amount of oligomeric seeds has formed. In the elongation process, the addition of more monomers leads to a structural change into elongated prefibrillar intermediates, eventually resulting in the formation of protofibrils [45, 105]. Different assembly processes of amyloid were indicated in different color of lines in Figure 3.

3.3.2. Hierarchical Pathway. Hierarchical aggregation, which happens after nucleation and elongation, is characterized by two or more protofibrils intertwining through interoligomer or interfibril interactions. They form higher ordered fibrils and eventually helical structures. Many species, CP $[17,118]$, human prion protein (PrPSc) $\mathrm{PrP}_{82-146}[16], \mathrm{PrP}_{106-126}$ [119], Ig light-chain [62], transthyretin peptide $\left(\mathrm{TTR}_{105-115}\right)$ [120], and $\beta$-lactoglobulin [51], were found to aggregate adopting a hierarchical pathway. Small or large oligomers undergo elongation and form heterogeneous structures, such as branchlike structures, annular-shaped oligomers, braided structures, and hairpin-like structures [17, 45, 46, 55]. Sbrana et al. [17] reported that branched structures were the disordered assembly of protruding segments. They also found that early annular-shaped oligomers seem to function as fundamental bricks in the hierarchical aggregation process [17]. The braided structure [62] consisting of winding protofibrils is usually observed in amyloid fibrillogenesis as well. In the selfassembly experiment of $\mathrm{A} \beta_{42}$ peptides [48], intermediate-like protofibrils were found to join the helical structure formation. Generally speaking, these heterogeneous morphologies and twisting periodicity indicated a complex hierarchical amyloid assembly process.

3.3.3. Lateral Aggregation. Increasing evidence suggests the existence of alternative pathways [38] in amyloid fibrillogenesis. One prominent example is lateral aggregation; it usually follows the elongation phase. Ceratoplatanin (CP) [17], PrP [109], glucagon [56, 95], insulin $[38,57], \mathrm{A} \beta_{1-42}[46,47]$, and $\beta 2$-microglobulin $[53,121]$ were found to aggregate laterally. In this pathway several protofibrils associate parallelly to form a ribbon that wraps around into a fibril (Figure 3, steps 10 and 12, type 3 structure). It was reported that fibrillar bundles formed loose tangles eventually leading to the formation of mature fibrils [57]. Fibrils containing laterally associated filaments were found to show a right-handed twist at one point [47]. A similar aggregation pathway was also found in the strand-swapping peptide 1 (SSP1). Nagarkar et al. [55] reported the lateral self-assembly of SSP1 dimers via $\mathrm{H}$ bond interaction along the fibril's long axis. Kad et al. [106] reported that four protofibrils associated laterally wound into 


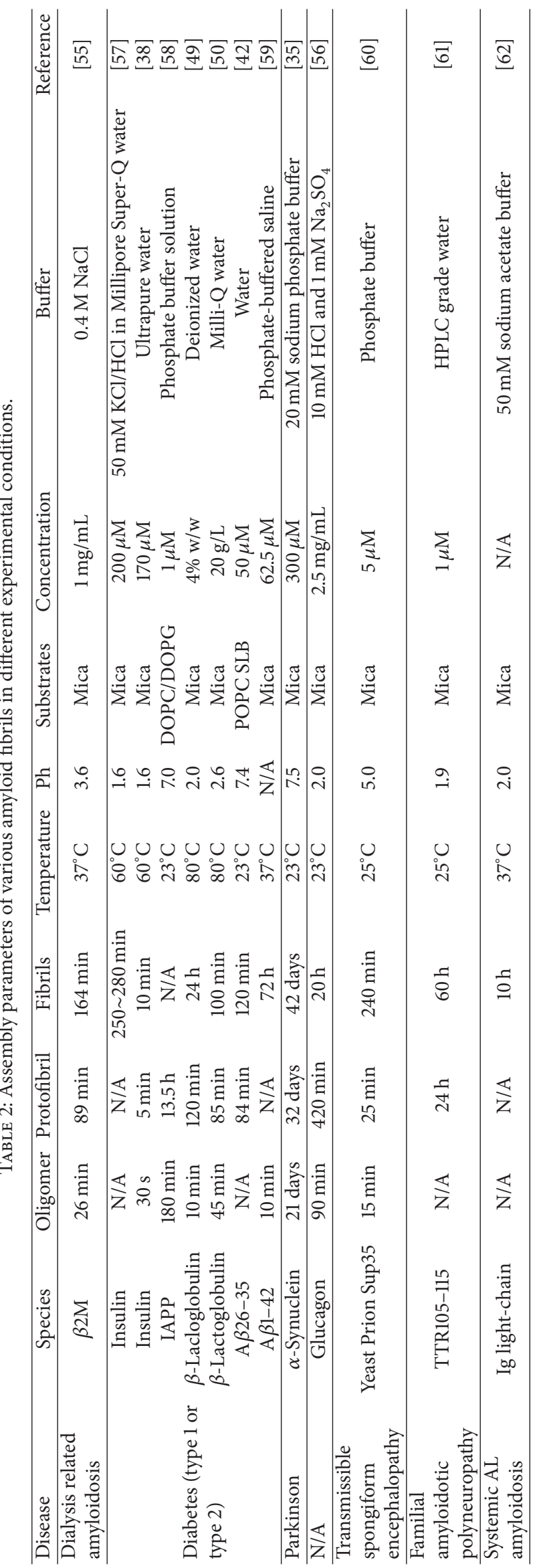




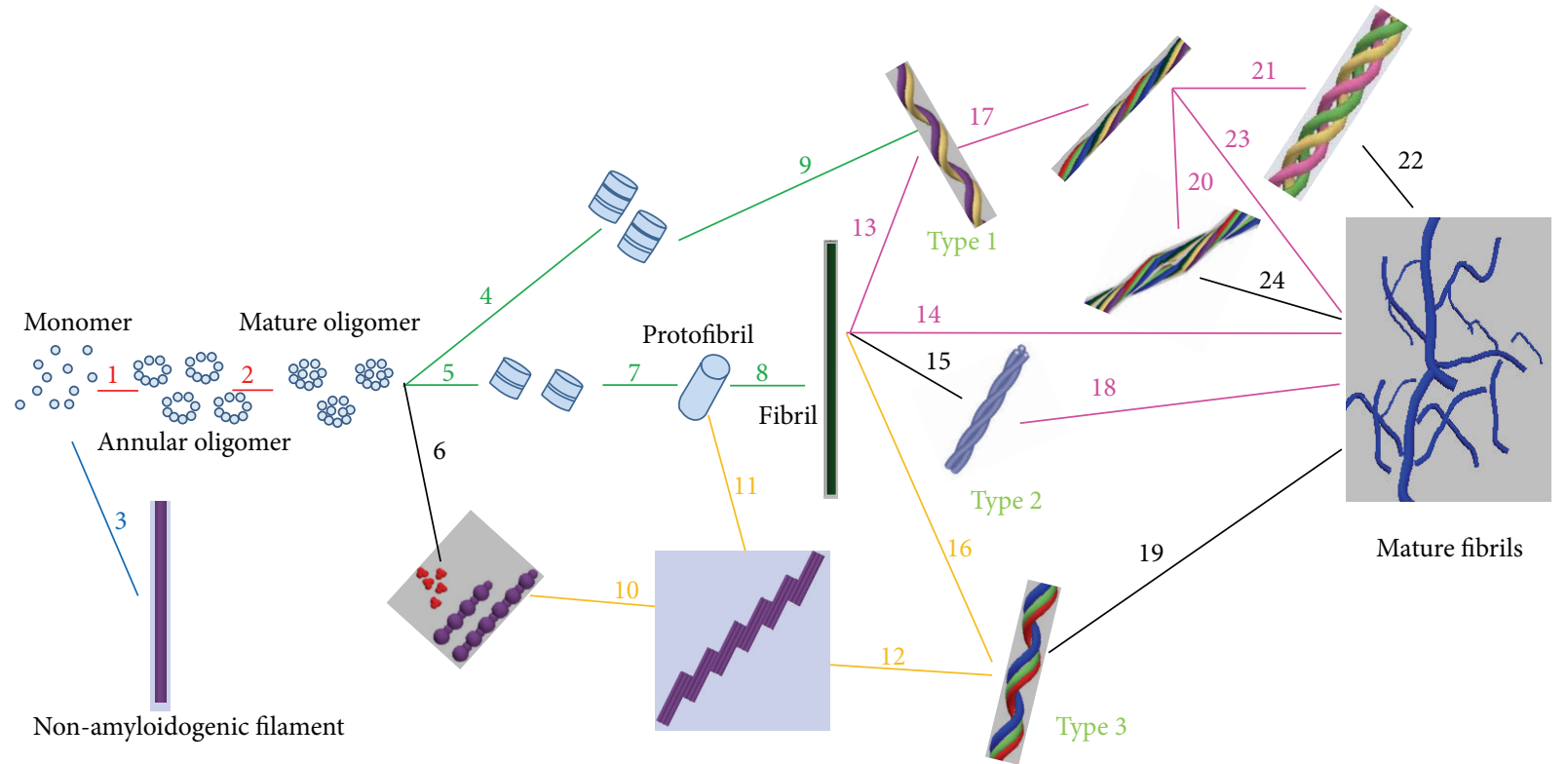

Time (nonlinear scale)

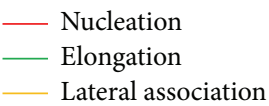

- Hierarchical aggregation

L Lateral association

FIgURE 3: Model proposed based on various models in the investigation of numerous amyloid aggregations. There are five processes before the formation of mature fibrils: nucleation [56] (steps 1 and 2 in red lines), elongation [17] (steps 4, 5, 7, 8, and 9 in green lines), lateral association (steps 10, 11, 12, and 16 in yellow lines), hierarchical aggregation $[15,38,53]$ (steps 13, 14, 17, 18, 20, 21, and 23 in purple lines), and off-pathway [63] (step 3 in blue line).

a twisted-ribbon shape with a clear periodicity, but there was no suggestion that lateral aggregation of smaller species was detected [49].

3.3.4. Multipathway. Multipathway is the combination of all pathways mentioned above: monomers conformationally change and merge into oligomers (Figure 3, steps 1 and 2); then oligomers longitudinally aggregate leading to protofibrils (Figure 3, steps 4, 5, and 7). Finally protofibrils laterally aggregate into protofibrils (Figure 3, steps 6, 10, and 11) [122]. Homogeneous protofibrils undergo elongation to form higher ordered mature fibrils (Figure 3, steps 13, 15, and 16) and finally lead to complex blocks. Hierarchical and lateralaggregating structures were frequently observed in various kinds of amyloid fibrils [15-17, 36, 38, 45, 48, 53, 56, 57, 62, 95, 109, 111-113, 123].

In the off-pathway assembly, soluble monomers or oligomers directly construct fibrils [63] without the "seedlike" aggregation (Figure 3, step 3). Natalello et al. [16] reported that the linear $\operatorname{PrP}_{82-146}$ aggregates formed by oligomers aligning which suggested an off-pathway assembly. The main differences between on- and off-pathway oligomers are mainly their sizes and shapes. So, it is critical to clarify whether the aggregation is based on a nucleation phase and seeds or the formation of an active small oligomer.
On-pathway aggregation is characterized by the appearance of homogeneous nuclei, followed by elongation. At the same time, three types of fibrils (Figure 3) were found during the later stage of the aggregation process. These different types represent distinctive structures: type 1 is formed by two twined protofibrils; type 2 is formed by three twined protofibrils; and type 3 is formed by several parallel protofibrils laterally associated together. Several type 1 fibrils rearrange into intertwined style fibrils occasionally. Based on associated segments forming larger structures, Segers-Nolten et al. [36] proposed a segment pathway, indicating a multipathway assembly for $\alpha$-synuclein. Jansen et al. [38] revealed that insulin amyloidogenesis in vitro involved a multipathway assembling scheme, in which native dimers were formed by either hierarchical intertwining or lateral interaction. A similar observation was made by Mauro et al. [57]. The size and shape of oligomers were measured to identify different distinctive pathways. However, it could not be distinguished [55] whether the hierarchical or parallel fibrils were lacking structurally different nucleating centers. Although various models have been proposed, the detailed mechanism needs further exploration such as amyloids' aggregation and interor intramolecule interactions affected by constituent peptides or chemical chaperones. 
3.4. Influencing Factors of Assembly. High-resolution AFM has been used in many characterization studies, aimed at the morphology and assembly pathway of amyloid fibrils and the effects of chemicals and chaperones $[14,25,73,124-$ 126]. Concentration [36, 51, 96, 127-129], substrate [130], temperature $[38,49,50,57,131], \mathrm{pH}$ value $[54,106,121$, $132,133]$, ionic strength $[96,99,129,134,135]$, and stirring time and addition of denaturing agents $[24,50,82,115$, $119,128,136]$ are important factors affecting the formation of various aggregates. For example, different substrates can affect the orientation of amyloid fibrillogenesis [4]; solvent conditions play critical roles in amyloid aggregating propensity, rate, and structural formation. In order to decipher the molecular mechanisms and develop better strategies to modulate aggregation, it is imperative to learn the effects of environmental conditions on structure, molecular assembly process, activities, and growth kinetics. In this section, we will have a closer look on these experimental factors.

3.4.1. Concentration Effect. Many trials indicated that the concentration of amyloid peptides played a prominent role in amyloid aggregation. Although differences in concentration are correlated to the corresponding disease in vivo, their precise relation is not well-known. Previous work showed that the self-assembling rate of amyloid increased with the increasing of its solution concentration [137]. Segers-Nolten et al. [36] found that $\alpha$-synuclein shows relatively normal function at low concentrations, but it is apt to transform into a pathogenic species at high concentrations. There are a large number of experiments looking into surface density and concentration of the incubation solution [36, 51, 96, 127-129]. These experiments indicate that proteins form well-defined fibrils in low peptide concentrations with lower aggregation rates than that in a higher concentration. So, the amyloid fibril formation can be accelerated through increasing either surface density or the concentration in incubation solution [127]. In the same way, Pazzagli et al. [118] systemically studied the lag-phases in different concentrations and found that the transition time in higher concentration $(1.3 \mathrm{Mm}$, lagphase time being 6 hours) was sharply shortened comparing with that of the lower concentration $(0.54 \mathrm{mM}$, lag-phase time being longer than ten days). The surface density of amyloid self-assembled fibrils can be adjusted by tuning the bulk concentration, and many groups showed that dense fiber-networks can be constructed starting with high peptide concentrations [96, 129]. However, insulin is an exception, as obvious structure change was observed for two enormously different concentrations [57].

3.4.2. Temperature Effect. Temperature, in general, can affect morphology, growth rate, stability, and activity of heterogeneous fibrils and eventually change the overall process of amyloid aggregation $[38,49,50,57,131]$. For example, various structures were observed upon increasing the temperature to $70^{\circ} \mathrm{C}$, among them long straight rods, twisted-ribbonlike structures, rod bundles, and rope-like structures [38]. Increasing temperature can not only shorten the aggregation lag-phase [118] but also affect the height of the assembled fibrils [138]. In contrast, nucleation was inhibited at low temperatures. Pazzagli et al. [118] investigated the ordered aggregates of ceratoplatanin and found that lag-time decreased from 30 to 10 days when incubation temperature was increased from $37^{\circ} \mathrm{C}$ to $50^{\circ} \mathrm{C}$. Palhano et al. [60] employed $4^{\circ} \mathrm{C}$ and $25^{\circ} \mathrm{C}$ to investigate the effect of temperature on the process of amyloid aggregation. Their AFM results showed that the aggregations were higher at $4^{\circ} \mathrm{C}$ than at $25^{\circ} \mathrm{C}$. At the same time they revealed that amyloid fibril were, on average, shorter at $4^{\circ} \mathrm{C}$ than at $25^{\circ} \mathrm{C}$. The reason for this phenomenon is that the activity of amyloid can be influenced by temperature [131]. Native $\mathrm{M} \beta$ activity remained stable up to $70^{\circ} \mathrm{C}$, but its activity abruptly decreased at a temperature ranging from $70^{\circ} \mathrm{C}$ to $80^{\circ} \mathrm{C}$. Bellezza also found that the main activity of adsorbed $\mathrm{M} \beta$ decreased abruptly between $30^{\circ} \mathrm{C}$ and $60^{\circ} \mathrm{C}$, while the activity reduced slightly below $30^{\circ} \mathrm{C}$ or higher than $60^{\circ} \mathrm{C}$. Mauro et al. [57] studied the temperature impact on insulin and found the assembly adopting double quenching experiments. Their results indicated that the double quenching allowed the growth of a few long fibrils.

3.4.3. pH Effect. An acidic environment is beneficial for the amyloid formation $[35,87,106,128]$, and there are plenty of studies modulating amyloid aggregation through varying $\mathrm{pH}$ values [54, 106, 121, 132, 133]. In these studies, researchers found that amyloid fibrils were not stable in either acidic or alkaline solution environments, which easily led to the conformational changes. Many investigations suggested that the nanostructure of various amyloid assemblies could be modified through adjusting $\mathrm{pH}$ value. Bortolini et al. [133] built different nanostructures of peptide with three different kinds of residues by tuning the $\mathrm{pH}$ value of the solution [133]. McAllister et al. [87] reported that decreasing $\mathrm{pH}$ value resulted in the prominent increase of the interaction among protein molecules of $\mathrm{A} \beta(1-40)$ peptide, $\alpha$-synuclein, and lysozyme. This leads to a dramatic increase in aggregation rate at the proper $\mathrm{pH}$ value. For most peptides there are large differences in reaction speed and product morphology between acidic and alkaline conditions. Short fibrils or small globular aggregates were found at $\mathrm{pH} 2.0$, and fibrillar structures were found at $\mathrm{pH} 2.7$, but there was no fibril or large aggregate observed at $\mathrm{pH}$ 3.7. Hong et al. [54] studied two kinds of amyloid aggregates at $\mathrm{pH}$ values varying from 4 to 11. Hong et al. found that KAK16-IV formed globular assemblies in neutral $\mathrm{pH}$ environments, which changed into fibrils under alkaline conditions. Another mutant, EAK16II, did not exhibit any apparent changes. Jenko et al. [139] established that Stefin B started to form fibrils at $\mathrm{pH}$ 5, whereas Stefin A needed to be acidified to a $\mathrm{pH}$ value of less than 2.5. Most tests showed that acidic environments were conducive to fibrils formation, but the transformation of Stefin B from protofibrils into mature fibrils was inhibited at acidic solution [128].

3.4.4. Solvent Effect. AFM experiments suggest that the incubating medium plays an important role in the assembly process [47, 49-51, 97, 127, 140, 141]. Chaudhary et al. [97] 
reported that AcPHF6 could be organized into fibrillar structures when the sample peptide was dissolved in $\mathrm{MeOH}$, TFE, or HFIP. Gosal et al. [49] found that the aggregation rate of $\beta$-lactoglobulin was correlated with solvents used in experiments. There are more fibrillar structures presented in TFE-water mixed solvent in contrast to other alcohols. Gelling propensity was related to solvents: methanol > ethanol $>$ propanol $>$ TFE. At $\mathrm{pH} 7$, the tendency of $\beta$ lactoglobulin to form a gel was higher in propanol than that in ethanol, methanol, or TFE. The fibrillar aggregates formed in TFE-water mixtures; imaged with negative-staining EM these TFE-induced fibrils showed worm-like and granular structures [49]. Nichols et al. [43] found rapid assembly of amyloid- $\beta$ peptide at a liquid/liquid interface which induced unstable $\beta$-sheet fibers. The association rate of $\mathrm{A} \beta_{1-40}$ in a two-phase system with chloroform was 1 2 orders of magnitude faster than that in the buffer alone. Daniela et al. [50] reported that $\beta$-lactoglobulin formed different amorphous aggregates in alcohols and TFE. The concentration of TFE also influenced the assembly process [128]. The aggregating rate of human Stefin B fibrils was accelerated in a solution containing alcohol, but, in contrast to other proteins, the lagphase did not change TFE concentration.

3.4.5. Cations Effect. Metal ions such as $\mathrm{Fe}^{3+}, \mathrm{Cu}^{2+}, \mathrm{K}^{+}$, and $\mathrm{Na}^{+}$significantly affect the process of amyloid aggregation and morphology $[96,99,129,134,135]$. Ions function as an inhibitor or accelerator to various amyloid species, and fibril shapes may be influenced by varying the metal ions concentration. Precisely how the ions effect the aggregation is still controversial. Ryu et al. [96] reported that the initial rate of amyloid fibrillation was accelerated by 6 times in the presence of $\mathrm{Fe}^{3+}$ ions, but ions might act as an inhibitor under other conditions. For example, high ion concentration inhibited amyloid aggregation of rat amylin [107]. In addition, disrupted adhesive nanofiber structures can be repaired by solutions containing divalent cations [127].

Apart from the effects on amyloid aggregation speed, the morphology is also influenced by cations [134], as they interfere with peptide-peptide interaction. For example, fibrillar structures tend to form at low $\mathrm{Cu}^{2+}$ concentration, but the amount of granular, amorphous aggregation increased rapidly at higher concentrations of $\mathrm{Cu}^{2+}$. Hong et al. [129] reported that the dimensions and surface tension of peptide nanostructures were influenced by the $\mathrm{NaCl}$ concentration in the solution. The orientation of amyloid aggregation on mica was affected by ions [99]; this was attributed to cooperative interaction of a positively charged $\mathrm{A} \beta_{25-35}$ peptide moiety binding to the mica lattice. They pointed out that $A \beta_{25-35-N 27 C}$ binding to mica was sensitive to the presence of cations and suggested that the increase of $\mathrm{NaCl}$ or $\mathrm{KCl}$ concentration could reduce the binding strength between fibrils and mica surface. Further research indicated that fibrils binding to mica were more sensitive to $\mathrm{K}^{+}$compared to $\mathrm{Na}^{+}$ions.

3.4.6. Denaturing Additives Effect. Various additives are usually employed to modulate the behaviors of amyloid fibrils through accelerating, inhibiting aggregation, or disassembling $[24,50,82,115,119,128,136]$. Some reversible changes can be accomplished $[127,142]$ by varying the concentration of additives. Different additives have been used to study their effects on various amyloids, such as the effect of $\mathrm{Zn}$, sulfated glycopolymers, $\mathrm{C}_{12} \mathrm{C}_{6} \mathrm{C}_{12} \mathrm{Br}_{2}$ micelles, Trimethylamine $\mathrm{N}$ oxide, and glycerol on $\mathrm{A} \beta$ peptide $[82,141-143]$, TFE on human stefin B [135], anionic lipid phosphatidylserine (PS) and cholesterol on amylin [24], antibody scFv on $\alpha$ synuclein, insulin, and $\beta$-amyloid $[136,142]$, chitotriose and NAG on HEWL [132], DTT and SDS/CTAB on lysozyme [144], metalloporphyrins on insulin [86], SSMs-ectoine and mannosylglyceramide (MGA) on $\mathrm{PrP}_{106-126}$ [119], and so forth. Though all additives affect the assembly process of amyloid, different additives act through different mechanisms on amyloids. Some additives affected the whole assembly process, whereas others acted at specific assembly stages.

Cho et al. [24] reported that the anionic lipid PS stimulated amyloid aggregation only at a certain stage. ScFv-6E enhanced the kinetic aggregation of httexl-51Q by binding and stabilizing the nascent fibrils which reduced the thermodynamic lag-time of fibrillogenesis [136]. Marcus et al. [145] suggested that the isolated $\mathrm{scFv}$ possibly targeted a shared fibrillar motif which might be the cross- $\beta$-sheet characteristic of amyloid fibrils. Further investigation suggested that those bonds appeared after lag-time stages. The random coil to $\beta$-sheet conformational transition of $\mathrm{A} \beta$ was rapidly accelerated by Trimethylamine $\mathrm{N}$ oxide and glycerol [82], but the final stage of amyloid formation was dominated by osmolyte-facilitated changes in $\mathrm{A} \beta$ hydration. Some additives function as inhibitors in amyloid aggregation. Cholesterol sequestered the amylin aggregation [24], metalloporphyrins inhibited insulin aggregation [86], and chelator of Zn induced a slow but nonfibrillar aggregation of globular A $\beta$ [142]. Kanapathipillai et al. [119] suggested a preferential exclusion mechanism of amyloid aggregation by adding denaturing agents. In their study, mixtures of ectoine and MGA, hydroxyectoine, and MG were employed to affect $\operatorname{PrP}_{106-126}$ amyloid formation process. The results indicated that the former could inhibit $\mathrm{PrP}_{106-126}$ amyloid formation whereas the latter could not. They found that hydroxyectoine and MG, respectively, possessed more hydrophilic features and negative charges because of their carboxyl group. In addition, PrP ${ }_{106-126}$, consisting of N-terminal polar heads and long hydrophobic tails, seemed to only interact with its polar head in most hydrophilic solutes. It was found that $\mathrm{A} \beta \mathrm{N}$-terminal hydrophilic domains could disassemble amyloid fibrils [116]. Similarly, mature $\mathrm{A} \beta_{1-40}$ fibrils could be disassembled by a cationic gemini surfactant, $\mathrm{C}_{12} \mathrm{C}_{6} \mathrm{C}_{12} \mathrm{Br}_{2}$ micelles, in vitro [115]. Synergistic, hydrophobic, and electrostatic interactions are responsible for the disassembling of $\mathrm{A} \beta_{1-40}$ fibrils. Tang et al. [146] reported the assembly-disassembly processes of $\alpha$ synuclein ( $\alpha$-Syn) fibrils in different solutions and chaotropic agent guanidinium chloride rapidly breaking the long $\alpha$-Syn fibrils into fragments.

3.4.7. Substrate Effect. AFM-based experiments indicated that identical species are apt to form different morphologies [52] at different rates [147] on distinctive substrates such as 
mica, graphite, gold, glass, lipid membranes, and cell surfaces. Growth rate, orientation, and deformation of the aggregation were greatly influenced by the substrates used in the experiments. Some correlations exist between substrates and amyloid fibrils conformation $[4,11,16,29,30,42,99,107,108,135$, $148,149]$. More and more results attributed this phenomenon to intermolecular interaction of static electronic interaction between amyloids and substrates [130, 135, 137, 150, 151]. Linear structures and uniform elongated sheets formed on mica and graphite substrates, respectively. At the same time, the orientation of assembled sheet structures can also be affected by substrates. The amount of fibrils, found in AFM images [148], suggested that the aggregation rate of protein covalently immobilized on a silicon surface was 4.6 times faster than that on a gold surface. Distinct hydrophilic and hydrophobic conformations formed on corresponding solid substrates. Right-handed helical orientation of beaded fibrils [47] formed on a hydrophobic interface, while left-handed helical orientation formed on a hydrophilic mica surface. However, $\mathrm{A} \beta 42$ could not form fibrils on the surface of planar lipid. The reason might be that mica is crystalline and has negatively charged surfaces but the lipid membrane has a soft and fluid nature. Zhang et al. [42] reported that $\mathrm{A} \beta_{26-35}$, respectively, formed large-scale, highly ordered, paralleloriented surface patterns on different lipid membranes. Their observation implied that the properties of lipid membranes, such as the fluidity, were associated with the parallel-oriented fibrogenesis. Wegmann et al. [30] and Karsai et al. [99] also reported that heterogeneous shapes occurred on cell surfaces. Kiselev et al. [148] revealed the deformation of protein molecules immobilized on mica surfaces, and they reported that some species were preferentially adsorbed on specific substrate defects, such as edges of defects. Through myoglobin $(\mathrm{Mb})$ adsorption on $\mathrm{ZrO}_{2}-\mathrm{P}$ substrate, Bellezza et al. [131] found that $\mathrm{ZrO}_{2}-\mathrm{P}$ nanoparticles affected the morphology and the interaction which resulted in prefibrillar-like aggregates. Furthermore, Liang et al. [61] found that differentstaged $A \beta$ had distinctive mechanisms of aggregation. At present, it is hypothesized that hydrophobicity is the main driving force of $\mathrm{A} \beta$ and liposome interaction.

3.4.8. Other Disturbances' Effect. Other factors, such as stirring, dehydration, and magnetic fields, were found to have effects on the amyloid aggregation as well. Stirring accelerated the formation of amyloid fibrils [147]. The internal structure of $\mathrm{A} \beta_{1-42}$ fibrils was changed by dehydration [152]. Hill [153] reported that aligned aromatic peptide tubes formed in strong magnetic fields, which benefited the fibril growth [139].

\section{Intramolecular Interaction}

Apart from the studies using AFM imaging to investigate intermolecular interactions, the intramolecular interactions were explored by AFM-based single-molecule force spectroscopy (SMFS). SMFS has been employed to probe the mechanical properties of various biological molecules, such as polysaccharides, DNA, and proteins. A unique mechanical response representing the fingerprint of the corresponding molecule was discovered. For example, the length transitions in the mechanical fingerprint of polysaccharides were attributed to the shift of individual pyranose rings from chair to boat or inverted chair conformations [154, 155]. The extensive conformational change of a B-S transition was observed in stretching dsDNA. Moreover, direct measurement of intramolecular interactions, including donoracceptor, ionic, conjugational, and hydrophobic interactions, has been performed. Recently, various amyloid fibrils were probed. The mechanical properties of $\beta$-sheets were gradually observed with SMFS.

4.1. Amyloid Fibrils' Unfolding. Force measurement of amyloids focused on the $\beta$-sheet structures existing in $\mathrm{A} \beta_{25-35}$ and $\mathrm{A} \beta_{1-40}$ peptides [29], $\alpha$-synuclein [64], TTR $105-115$ [156], unicellular Subaerial Algae [122], terrestrial alga Prasiola linearis [83, 157], and glucagon [117]. Figure 4 illustrates the unfolding mechanical signatures of $\alpha$-Syn (there are three tandem titin I27 domains on either side of the $\alpha$-Syn sequence [64] in Figure 4(a)). The repetitive saw-tooth patterns during the stretch process represent the typical mechanical response of multidomain proteins of titin [158]. During the stretch process, the increasing and the abrupt force drop in each sawtooth pattern reveal that one I27 domain was stretched and unzipped. So, the six peaks on left side with identical spacing and amplitude indicate the regular inner structure of $\beta$-sheet (Figure 4). The last peak in the saw-tooth pattern corresponds to the detachment activity between the molecule and the tip. The number of unzipping peaks agreed with that of the I27 domains composing the protein, and the indistinguishable peaks suggested a series of identical structures. The spacing gap between each saw-tooth pattern in figure is $28 \mathrm{~nm}$ for tandem titin I27 domains, and the approximate force value of the six unzipping peaks is $200 \mathrm{nN}$.

For other amyloid fibrils, the force patterns exhibit different spacing and rupture forces. The saw-tooth peaks were regularly spaced with a separation of approximately $36 \mathrm{~nm}$ for unicellular Subaerial Algae, $56 \pm 9 \mathrm{~nm}$ for cement of the barnacle Amphibalanus amphitrite [159], $36.04 \pm 6.5 \mathrm{~nm}$ for terrestrial alga Prasiola linearis [157], $34.9 \pm 5.6 \mathrm{~nm}$ for Prasiola linearis [83], and $1600 \pm 76 \mathrm{~nm}$ for glucagon [117]. The average magnitude of the force peaks of terrestrial alga Prasiola linearis was found to be $244 \pm 36 \mathrm{pN}$ at the stretching rate of 2.5 to $3.0 \mu \mathrm{m} / \mathrm{s}, 235 \pm 12 \mathrm{pN}$ for glucagon at the loading rate of $2 \mu \mathrm{m} / \mathrm{s}, 3.5 \mathrm{nN}$ for stretching cement, and $20 \mathrm{pN}$ for TTR fibrils at the loading rate of $30 \mathrm{~nm} / \mathrm{s}$. The magnitude of the force, at this extension rate, would be the characteristic of the previous systems containing hydrogenbonded $\beta$-sheets. Each jump of the saw-tooth response was attributed to a "sacrificial bond" and "hidden length" [160]. The fingerprint of the force responses could be used to analyze the specific structure present in heterogeneous conformations [87]. In the study of stretching $A \beta_{25-35}$ and $\mathrm{A} \beta_{1-40}$ peptides, staircase-like force patterns were obtained. Kellermayer et al. [29] found that the force curves for two kinds of amyloid fibril were qualitatively similar. Comparing the statics data of mechanical response, $\mathrm{A} \beta_{25-35}$ and $\mathrm{A} \beta_{1-40}$ exhibited the characteristics of the smallest plateau forces of $33 \pm 7 \mathrm{pN}$ and $41 \pm 7 \mathrm{pN}$, respectively. They suggested that 


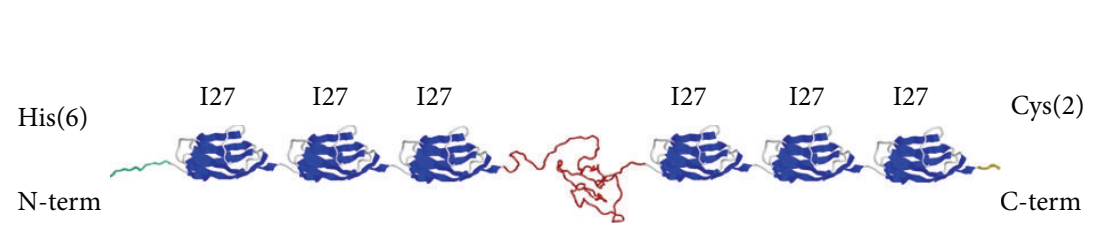

(a)

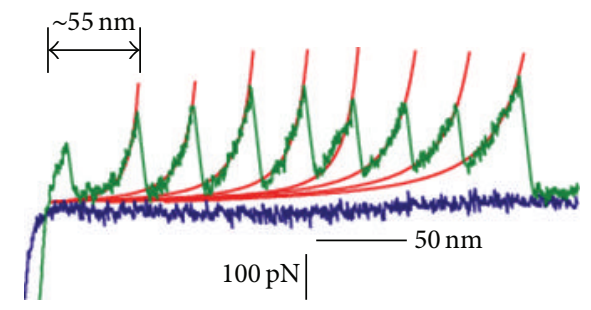

(c)

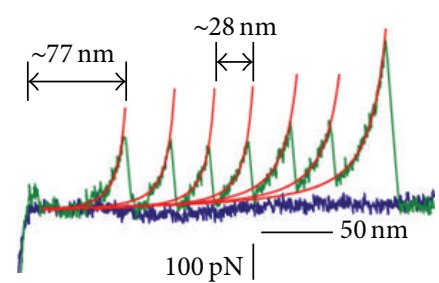

(b)

FiguRE 4: (Images of (a), (b), and (c) in Figure 4 are parts of figures from reference.) The mechanical signatures of $\alpha$-Syn conformational classes recorded by SMFS [64]. (a) Schematic representation of the polyprotein constructs used in the work. (b) Example of curve characterized by a featureless region assigned to the stretching of $\alpha$-Syn moiety having, in this case, the mechanical properties of a random coil. (c) Example of the curves featuring the $\beta$-like signature of $\alpha$-Syn, showing seven practically indistinguishable unfolding events of similar magnitude and spacing.

the smallest force was the very unit for superimposing force pattern.

4.2. Mechanical Measurement. During the pulling process of SMFS, the mechanical response can be indirectly used to measure the semiflexible properties of molecules. Their quantification was performed by fitting a Worm-Like Chain (WLC) model for the semiflexible properties. The studies revealed the mean persistence length of $0.44 \pm 0.08 \mathrm{~nm}$ for Coccomyxa sp., $0.38 \pm 0.07 \mathrm{~nm}$ for Glaphyrella trebouxiodes [122], $0.35 \pm 0.05 \mathrm{~nm}$ for barnacle cement [159], $0.38 \pm 0.06 \mathrm{~nm}$ for $\mathrm{A} \beta_{1-40}$ [29], $0.36 \pm 0.05 \mathrm{~nm}$ for $\alpha$-Syn [64], 0.57 for adhesive nanofibers [157], $0.34 \pm 0.18 \mathrm{~nm}$ for EPS [83], and $0.70 \pm 0.15 \mathrm{~nm}$ for glucagon [117]. Two kinds of Subaerial Algae with strong attachment to anthropogenic surfaces were selected to investigate the nanoscale adhesive properties by SMFS [157] technology. The mechanical data shows how amyloid provides cohesive strength to the adhesives, and this intrinsic mechanical property can be used to explain the attachment of these subaerial microalgae onto various surfaces in urban environments.

The stiffness of nanoscale structures was quantified using force indentation curves $[86,159,161,162]$. By fitting indentation data, typically the mechanical Hertz model [74], Young's modulus of the material could be obtained.

Beside the useful modulus property of amyloid, the basic force-distance curve can also provide rich information of samples. The reproducibility of the saw-tooth pattern when successive curves are taken at the same locations $[64,83,122$, 157] is strong point of view to prove that amyloid fibers are able to reassemble after being stretched. Dong et al. [117] suggested that the observed elasticity was due to a forceinduced conformational transition and the reversibility was attributed to the $\beta$-helical conformation of protofibrils which allows a high degree of extension.

Insulin fibrils exhibited a nearly elastic response to the compressive load which suggested lower packing density in amyloid fibrils [161] than that in protein crystals. The measured lower Young modulus indicated that insulin fibrils possess a looser internal packing compared to globular protein crystals and agree with the loose structure of $\beta 2$ microglobulin amyloid [163].

4.3. Effects of Experimental Conditions. Force responses are, in a similar fashion as the morphology, heavily influenced by experimental parameters such as loading rate, ionic concentration, $\mathrm{pH}$ value, and incubating time. Time-lapse AFM imaging and force spectroscopy have been performed to study the assembly process of $\mathrm{A} \beta_{1-40}$ fibrils under different experimental conditions in situ. $\alpha$-Synuclein, amyloid $\beta$ peptide $(\mathrm{A} \beta)$, and lysozyme were used to explore the $\mathrm{pH}$ value influence on interprotein interaction of amyloid aggregation [87]. It has been confirmed that the $\mathrm{pH}$ value for these conformational transitions coincided with $\mathrm{pH}$ values that led to changes in the pulling forces. The SMFS data showed that the attractive force between homologous protein molecules was minimal at a physiological $\mathrm{pH}$ value and increased dramatically at an acidic $\mathrm{pH}$ value. However, it has not been directly proven that the dramatic increase in interprotein interaction under acidic conditions was responsible for fibrillation.

\section{Summary and Outlook}

We reviewed the latest observations of inter- or intramolecular interactions of amyloid fibrils using AFM and AFM-based 
SMFS techniques. Various morphologies of amyloid fibrils, the assembly process, and the aggregating pathways were summarized in order to analyze their influence on amyloid fibrillogenesis. In addition, the fingerprint of mechanical response through AFM-based SMFS complements the information gained by topological AFM imaging. There is no doubt that SMFS combined with AFM provides a useful application in detecting inter- or intramolecular interactions. They opened a new path to explore fibrillogenesis, provide information of amyloid fibrils, and finally initiate a solution to curing neurological disordered diseases.

\section{Competing Interests}

The authors declare that they have no competing interests.

\section{Acknowledgments}

The authors acknowledge financial support from the National Natural Science Foundation of China (nos. U1304310 and 21373077), and Henan Natural Science Research Office of Education project (no. 12A180005 and no. 2010A140001).

\section{References}

[1] C. Bortolini and M. Dong, "Cystine oligomers successfully attached to peptide cysteine-rich fibrils," Frontiers of Chemical Science and Engineering, vol. 10, no. 1, pp. 99-102, 2016.

[2] J. Hardy and D. J. Selkoe, "The amyloid hypothesis of Alzheimer's disease: progress and problems on the road to therapeutics," Science, vol. 297, no. 5580, pp. 353-356, 2002.

[3] D. J. Selkoe, "Alzheimer's disease: genes, proteins, and therapy," Physiological Reviews, vol. 81, no. 2, pp. 741-766, 2001.

[4] J. Wang, Y. Cao, Q. Li, L. Liu, and M. Dong, "Size effect of graphene oxide on modulating amyloid peptide assembly," Chemistry - A European Journal, vol. 21, no. 27, pp. 9632-9637, 2015.

[5] X. Wang, J. K. Weber, L. Liu, M. Dong, R. Zhou, and J. Li, "A novel form of $\beta$-strand assembly observed in $A \beta$ 33-42 adsorbed onto graphene," Nanoscale, vol. 7, no. 37, pp. 1534115348, 2015.

[6] A. B. Singleton, M. Farrer, J. Johnson et al., " $\alpha$-synuclein locus triplication causes Parkinson's disease," Science, vol. 302, no. 5646, p. 841, 2003.

[7] G. Bates, "Huntingtin aggregation and toxicity in Huntington's disease," The Lancet, vol. 361, no. 9369, pp. 1642-1644, 2003.

[8] Y. P. Goldberg, H. Telenius, and M. R. Hayden, "The molecular genetics of Huntington's disease," Current Opinion in Neurology, vol. 7, no. 4, pp. 325-332, 1994.

[9] J. Collinge, "Prion diseases of humans and animals: their causes and molecular basis," Annual Review of Neuroscience, vol. 24, no. 1, pp. 519-550, 2001.

[10] M. Neumann, D. M. Sampathu, L. K. Kwong et al., "Ubiquitinated TDP-43 in frontotemporal lobar degeneration and amyotrophic lateral sclerosis," Science, vol. 314, no. 5796, pp. 130-133, 2006.

[11] H. F. Christoffersen, M. Andreasen, S. Zhang et al., "Scaffolded multimers of hIAPP ${ }_{20-29}$ peptide fragments fibrillate faster and lead to different fibrils compared to the free hIAPP $20-29$ peptide fragment," Biochimica et Biophysica Acta-Proteins and Proteomics, vol. 1854, no. 12, pp. 1890-1897, 2015.

[12] M. Anguiano, R. J. Nowak, and P. T. Lansbury Jr., "Protofibrillar islet amyloid polypeptide permeabilizes synthetic vesicles by a pore-like mechanism that may be relevant to type II diabetes," Biochemistry, vol. 41, no. 38, pp. 11338-11343, 2002.

[13] M. Chen, S. Zhang, Q. Liu et al., "An investigation into the formation of annular aggregates of human Islet amyloid polypeptide on tantalum oxide surfaces," Chemistry-A European Journal, vol. 18, no. 9, pp. 2493-2497, 2012.

[14] P. Liu, S. Zhang, C. Wang et al., "Co-assembly of human islet amyloid polypeptide (hIAPP)/insulin," Chemical Communications, vol. 48, no. 2, pp. 191-193, 2012.

[15] R. Khurana, C. Ionescu-Zanetti, M. Pope et al., "A general model for amyloid fibril assembly based on morphological studies using atomic force microscopy," Biophysical Journal, vol. 85, no. 2, pp. 1135-1144, 2003.

[16] A. Natalello, V. V. Prokorov, F. Tagliavini et al., "Conformational plasticity of the Gerstmann-Sträussler-Scheinker disease peptide as indicated by its multiple aggregation pathways," Journal of Molecular Biology, vol. 381, no. 5, pp. 1349-1361, 2008.

[17] F. Sbrana, L. Bongini, G. Cappugi et al., "Atomic force microscopy images suggest aggregation mechanism in cerato-platanin," European Biophysics Journal, vol. 36, no. 7, pp. 727-732, 2007.

[18] T. R. Serio, A. G. Cashikar, A. S. Kowal et al., "Nucleated conformational conversion and the replication of conformational information by a prion determinant," Science, vol. 289, no. 5483, pp. 1317-1321, 2000.

[19] F. J. Giessibl, "Advances in atomic force microscopy," Reviews of Modern Physics, vol. 75, no. 3, pp. 949-983, 2003.

[20] Y. Li, M. Dong, D. E. Otzen et al., "Influence of tunable external stimuli on the self-assembly of guanosine supramolecular nanostructures studied by atomic force microscope," Langmuir, vol. 25, no. 23, pp. 13432-13437, 2009.

[21] Y. Li, Y. Li, Y. Yao et al., “Two-dimensional scaffold layer formations on a solid surface through xanthan polysaccharide: temperature effect," Colloids and Surfaces B: Biointerfaces, vol. 74, no. 1, pp. 136-139, 2009.

[22] E. S. Andersen, M. Dong, M. M. Nielsen et al., "Self-assembly of a nanoscale DNA box with a controllable lid," Nature, vol. 459, no. 7243, pp. 73-76, 2009.

[23] M. Dong, S. Husale, and O. Sahin, "Determination of protein structural flexibility by microsecond force spectroscopy," Nature Nanotechnology, vol. 4, no. 8, pp. 514-517, 2009.

[24] W. J. Cho, B. P. Jena, and A. M. Jeremic, "Nano-scale imaging and dynamics of amylin-membrane interactions and its implication in type II diabetes mellitus," Methods in Cell Biology, vol. 90, pp. 267-286, 2008.

[25] L. Liu, L. Niu, M. Xu et al., "Molecular tethering effect of cterminus of amyloid peptide A $\beta 42$," ACS Nano, vol. 8, no. 9, pp. 9503-9510, 2014.

[26] M. Rief, F. Oesterhelt, B. Heymann, and H. E. Gaub, "Single molecule force spectroscopy on polysaccharides by atomic force microscopy," Science, vol. 275, no. 5304, pp. 1295-1297, 1997.

[27] A. Janshoff, M. Neitzert, Y. Oberdörfer, and H. Fuchs, "Force spectroscopy of molecular systems-single molecule spectroscopy of polymers and biomolecules," Angewandte ChemieInternational Edition, vol. 39, no. 18, pp. 3213-3237, 2000.

[28] T. R. Strick, J.-F. Allemand, D. Bensimon, and V. Croquette, "Stress-induced structural transitions in DNA and proteins," 
Annual Review of Biophysics and Biomolecular Structure, vol. 29, no. 1, pp. 523-543, 2000.

[29] M. S. Z. Kellermayer, L. Grama, Á. Karsai et al., "Reversible mechanical unzipping of amyloid $\beta$-fibrils," Journal of Biological Chemistry, vol. 280, no. 9, pp. 8464-8470, 2005.

[30] S. Wegmann, M. Miesbauer, K. F. Winklhofer, J. Tatzelt, and D. J. Muller, "Observing fibrillar assemblies on scrapie-infected cells," Pflügers Archiv-European Journal of Physiology, vol. 456, no. 1, pp. 83-93, 2008.

[31] T. Fukuma, A. S. Mostaert, L. C. Serpell, and S. P. Jarvis, "Revealing molecular-level surface structure of amyloid fibrils in liquid by means of frequency modulation atomic force microscopy," Nanotechnology, vol. 19, no. 38, Article ID 384010 , 2008.

[32] D. Radovan, V. Smirnovas, and R. Winter, "Effect of pressure on islet amyloid polypeptide aggregation: revealing the polymorphic nature of the fibrillation process," Biochemistry, vol. 47, no. 24, pp. 6352-6360, 2008.

[33] S. Bhattacharya, J. Naveena Lavanya Latha, R. Kumresan, and S. Singh, "Cloning and expression of human islet amyloid polypeptide in cultured cells," Biochemical and Biophysical Research Communications, vol. 356, no. 3, pp. 622-628, 2007.

[34] T. T. Ding, S.-J. Lee, J.-C. Rochet, and P. T. Lansbury Jr., "Annular $\alpha$-synuclein protofibrils are produced when spherical protofibrils are incubated in solution or bound to brain-derived membranes," Biochemistry, vol. 41, no. 32, pp. 10209-10217, 2002.

[35] M. M. Apetri, N. C. Maiti, M. G. Zagorski, P. R. Carey, and V. E. Anderson, "Secondary structure of $\alpha$-synuclein oligomers: characterization by Raman and atomic force microscopy," Journal of Molecular Biology, vol. 355, no. 1, pp. 63-71, 2006.

[36] I. Segers-Nolten, K. van der Werf, M. van Raaij, and V. Subramaniam, "Quantitative characterization of protein nanostructures using atomic force microscopy," in Proceedings of the 29th Annual International Conference of the IEEE Engineering in Medicine and Biology Society (EMBS '07), pp. 6608-6611, IEEE, Lyon, France, August 2007.

[37] C. Ortiz, D. Zhang, A. E. Ribbe, Y. Xie, and D. Ben-Amotz, "Analysis of insulin amyloid fibrils by Raman spectroscopy," Biophysical Chemistry, vol. 128, no. 2-3, pp. 150-155, 2007.

[38] R. Jansen, W. Dzwolak, and R. Winter, "Amyloidogenic selfassembly of insulin aggregates probed by high resolution atomic force microscopy," Biophysical Journal, vol. 88, no. 2, pp. 13441353, 2005.

[39] M.-S. Lin, H.-M. Chiu, F.-J. Fan et al., "Kinetics and enthalpy measurements of interaction between $\beta$-amyloid and liposomes by surface plasmon resonance and isothermal titration microcalorimetry," Colloids and Surfaces B: Biointerfaces, vol. 58, no. 2, pp. 231-236, 2007.

[40] P. Mesquida, C. K. Riener, C. E. MacPhee, and R. A. McKendry, "Morphology and mechanical stability of amyloid-like peptide fibrils," Journal of Materials Science: Materials in Medicine, vol. 18, no. 7, pp. 1325-1331, 2007.

[41] P. Mesquida, E. M. Blanco, and R. A. McKendry, "Patterning amyloid peptide fibrils by AFM charge writing," Langmuir, vol. 22, no. 22, pp. 9089-9091, 2006.

[42] L. Zhang, J. Zhong, L. Huang, L. Wang, Y. Hong, and Y. Sha, "Parallel-oriented fibrogenesis of a $\beta$-sheet forming peptide on supported lipid bilayers," Journal of Physical Chemistry B, vol. 112, no. 30, pp. 8950-8954, 2008.

[43] M. R. Nichols, M. A. Moss, D. K. Reed, J. H. Hoh, and T. L. Rosenberry, "Rapid assembly of amyloid- $\beta$ peptide at a liquid/ liquid interface produces unstable $\beta$-sheet fibers," Biochemistry, vol. 44, no. 1, pp. 165-173, 2005.

[44] N. Benseny-Cases, M. Cócera, and J. Cladera, "Conversion of non-fibrillar $\beta$-sheet oligomers into amyloid fibrils in Alzheimer's disease amyloid peptide aggregation," Biochemical and Biophysical Research Communications, vol. 361, no. 4, pp. 916-921, 2007.

[45] I. A. Mastrangelo, M. Ahmed, T. Sato et al., "High-resolution atomic force microscopy of soluble A $\beta 42$ oligomers," Journal of Molecular Biology, vol. 358, no. 1, pp. 106-119, 2006.

[46] M. Arimon, I. Díez-Pérez, M. J. Kogan et al., "Fine structure study of A $\beta 1-42$ fibrillogenesis with atomic force microscopy," The FASEB Journal, vol. 19, no. 10, pp. 1344-1346, 2005.

[47] Z. Wang, C. Zhou, C. Wang, L. Wan, X. Fang, and C. Bai, "AFM and STM study of $\beta$-amyloid aggregation on graphite," Ultramicroscopy, vol. 97, no. 1-4, pp. 73-79, 2003.

[48] Z. Wang, L. Wan, C. Zhou, X. Fang, C. Wang, and C. Bai, "Study of $\beta$-amyloid adsorption and aggregation on graphite by STM and AFM," Chinese Science Bulletin, vol. 48, no. 5, pp. 437-440, 2003.

[49] W. S. Gosal, A. H. Clark, and S. B. Ross-Murphy, "Fibrillar $\beta$-lactoglobulin gels-part 1: fibril formation and structure," Biomacromolecules, vol. 5, no. 6, pp. 2408-2419, 2004.

[50] O. Daniela, W. Lizhe, B. André, M. Edmond, and M. A. E. Auty, "Characterization $\beta$-lactoglobulin fibrillar assembly using atomic force microscopy polyacrylamide gel electrophoresis, and in situ fourier transform infrared spectroscopy," Journal of Agricultural and Food Chemistry, vol. 58, no. 6, pp. 3667-3673, 2010.

[51] W. S. Gosal, A. H. Clark, P. D. A. Pudney, and S. B. RossMurphy, "Novel amyloid fibrillar networks derived from a globular protein: $\beta$-lactoglobulin," Langmuir, vol. 18, no. 19, pp. 7174-7181, 2002.

[52] S. E. Radford, W. S. Gosal, and G. W. Platt, "Towards an understanding of the structural molecular mechanism of $\beta 2$ microglobulin amyloid formation in vitro," Biochimica et Biophysica Acta (BBA)_Proteins and Proteomics, vol. 1753, no. 1, pp. 51-63, 2005.

[53] N. M. Kad, S. L. Myers, D. P. Smith, D. A. Smith, S. E. Radford, and N. H. Thomson, "Hierarchical assembly of $\beta 2$-microglobulin amyloid in vitro revealed by atomic force microscopy," Journal of Molecular Biology, vol. 330, no. 4, pp. 785-797, 2003.

[54] Y. Hong, R. L. Legge, S. Zhang, and P. Chen, "Effect of amino acid sequence and $\mathrm{pH}$ on nanofiber formation of self-assembling peptides EAK16-II and EAK16-IV," Biomacromolecules, vol. 4, no. 5, pp. 1433-1442, 2003.

[55] R. P. Nagarkar, R. A. Hule, D. J. Pochan, and J. P. Schneider, "De novo design of strand-swapped $\beta$-hairpin hydrogels," Journal of the American Chemical Society, vol. 130, no. 13, pp. 4466-4474, 2008.

[56] M. Dong, M. B. Hovgaard, S. Xu, D. E. Otzen, and F. Besenbacher, "AFM study of glucagon fibrillation via oligomeric structures resulting in interwoven fibrils," Nanotechnology, vol. 17, no. 16, pp. 4003-4009, 2006.

[57] M. Mauro, E. F. Craparo, A. Podestà et al., "Kinetics of different processes in human insulin amyloid formation," Journal of Molecular Biology, vol. 366, no. 1, pp. 258-274, 2007.

[58] F. Evers, C. Jeworrek, S. Tiemeyer et al., "Elucidating the mechanism of lipid membrane-induced IAPP fibrillogenesis and its inhibition by the red wine compound resveratrol: a 
synchrotron X-ray reflectivity study," Journal of the American Chemical Society, vol. 131, no. 27, pp. 9516-9521, 2009.

[59] I. H. Cheng, K. Scearce-Levie, J. Legleiter et al., "Accelerating amyloid- $\beta$ fibrillization reduces oligomer levels and functional deficits in Alzheimer disease mouse models," Journal of Biological Chemistry, vol. 282, no. 33, pp. 23818-23828, 2007.

[60] F. L. Palhano, C. B. Rocha, A. Bernardino et al., "A fluorescent mutant of the NM domain of the yeast prion Sup35 provides insight into fibril formation and stability," Biochemistry, vol. 48, no. 29, pp. 6811-6823, 2009.

[61] Y. Liang, S. Z. Jasbi, S. Haftchenary, S. Morin, and D. J. Wilson, "Binding interactions in early- and late-stage amyloid aggregates of TTR(105-115)," Biophysical Chemistry, vol. 144, no. 1-2, pp. 1-8, 2009.

[62] C. Lonescu-Zanetti, R. Khurana, J. R. Gillespie et al., "Monitoring the assembly of Ig light-chain amyloid fibrils by atomic force microscopy," Proceedings of the National Academy of Sciences of the United States of America, vol. 96, no. 23, pp. 13175-13179, 1999.

[63] S. Hess, S. L. Lindquist, and T. Scheibel, "Alternative assembly pathways of the amyloidogenic yeast prion determinant Sup35NM," EMBO Reports, vol. 8, no. 12, pp. 1196-1201, 2007.

[64] M. Sandal, F. Valle, I. Tessari et al., "Conformational equilibria in monomeric $\alpha$-synuclein at the single-molecule level," PLoS Biology, vol. 6, no. 1, article e6, 2008.

[65] G. Binnig, C. F. Quate, and C. Gerber, "Atomic force microscope," Physical Review Letters, vol. 56, no. 9, pp. 930-933, 1986.

[66] A. Alessandrini and P. Facci, "AFM: a versatile tool in biophysics," Measurement Science and Technology, vol. 16, no. 6, pp. R65-R92, 2005.

[67] W. A. Linke and A. Grützner, "Pulling single molecules of titin by AFM - recent advances and physiological implications," Pflügers Archiv: European Journal of Physiology, vol. 456, no. 1, pp. 101-115, 2008.

[68] Q. Li, J. Song, M. Saura-Múzquiz, F. Besenbacher, M. Christensen, and M. Dong, "Magnetic properties of strontium hexaferrite nanostructures measured with magnetic force microscopy," Scientific Reports, vol. 6, Article ID 25985, 2016.

[69] H. Liang, G. Zeng, Y. Li et al., "Exploring the complex mechanical properties of xanthan scaffolds by AFM-based force spectroscopy," Beilstein Journal of Nanotechnology, vol. 5, no. 1, pp. 365-373, 2014.

[70] F. Lippert, D. M. Parker, and K. D. Jandt, "In vitro demineralization/remineralization cycles at human tooth enamel surfaces investigated by AFM and nanoindentation," Journal of Colloid and Interface Science, vol. 280, no. 2, pp. 442-448, 2004.

[71] D. Xia, S. Zhang, E. Nielsen et al., "The ultrastructures and mechanical properties of the descement's membrane in fuchs endothelial corneal dystrophy," Scientific Reports, vol. 6, Article ID 23096, 2016.

[72] J. P. Froning, D. Xia, S. Zhang, E. Lægsgaard, F. Besenbacher, and M. Dong, "Piezoelectric oscillation sensor based noncontact atomic force microscope for imaging in both ambient and liquid environments," Journal of Vacuum Science and Technology B: Nanotechnology and Microelectronics, vol. 33, no. 2, Article ID 021801, 2015.

[73] M. Andreasen, K. K. Skeby, S. Zhang et al., "The importance of being capped: terminal capping of an amyloidogenic peptide affects fibrillation propensity and fibril morphology," Biochemistry, vol. 53, no. 44, pp. 6968-6980, 2014.
[74] A. Ashkin, K. Schutze, J. M. Dziedzic, U. Euteneuer, and M. Schliwa, "Force generation of organelle transport measured in vivo by an infrared laser trap," Nature, vol. 348, no. 6299, pp. 346-348, 1990.

[75] E. Evans, K. Ritchie, and R. Merkel, "Sensitive force technique to probe molecular adhesion and structural linkages at biological interfaces," Biophysical Journal, vol. 68, no. 6, pp. 2580-2587, 1995.

[76] A. Kishino and T. Yanagida, "Force measurements by micromanipulation of a single actin filament by glass needles," Nature, vol. 334, no. 6177, pp. 74-76, 1988.

[77] S. B. Smith, L. Finzi, and C. Bustamante, "Direct mechanical measurements of the elasticity of single DNA molecules by using magnetic beads," Science, vol. 258, no. 5085, pp. 1122-1126, 1992.

[78] P. Hinterdorfer and Y. F. Dufrêne, "Detection and localization of single molecular recognition events using atomic force microscopy," Nature Methods, vol. 3, no. 5, pp. 347-355, 2006.

[79] M. S. Z. Kellermayer, Á. Karsai, Ü. Murvai, S. Erdélyi-Bótor, J. Kardos, and R. H. Pires, "Single-molecule studies of amyloidogenic proteins," in Single-Molecule Studies of Proteins, A. F. Oberhauser, Ed., vol. 2 of Biophysics for the Life Sciences, pp. 169-210, Springer, New York, NY, USA, 2012.

[80] M. Kellermayer and C. F. Hazlewood, Tration Decreases (Table l.). The Increased Dry Mass of the AC, Water and Ions in Biological Systems, 2013.

[81] Y. Li, C. Zhu, J. Zhu et al., "Nanomechanics of phospholipid LB film studied layer by layer with AFM," Chemistry Central Journal, vol. 8, no. 1, article 71, 2014.

[82] D.-S. Yang, C. M. Yip, T. H. J. Huang, A. Chakrabartty, and P. E. Fraser, "Manipulating the amyloid- $\beta$ aggregation pathway with chemical chaperones," The Journal of Biological Chemistry, vol. 274, no. 46, pp. 32970-32974, 1999.

[83] A. S. Mostaert, M. J. Higgins, T. Fukuma, F. Rindi, and S. P. Jarvis, "Nanoscale mechanical characterisation of amyloid fibrils discovered in a natural adhesive," Journal of Biological Physics, vol. 32, no. 5, pp. 393-401, 2006.

[84] P. Flory and M. Volkenstein, Statistical Mechanics of Chain Molecules, Wiley Online Library, 1969.

[85] C. Bouchiat, M. D. Wang, J.-F. Allemand, T. Strick, S. M. Block, and V. Croquette, "Estimating the persistence length of a wormlike chain molecule from force-extension measurements," Biophysical Journal, vol. 76, no. 1, pp. 409-413, 1999.

[86] S. P. Sibley, K. Sosinsky, L. E. Gulian, E. J. Gibbs, and R. F. Pasternack, "Probing the mechanism of insulin aggregation with added metalloporphyrins," Biochemistry, vol. 47, no. 9, pp. 2858-2865, 2008.

[87] C. McAllister, M. A. Karymov, Y. Kawano et al., "Protein interactions and misfolding analyzed by AFM force spectroscopy," Journal of Molecular Biology, vol. 354, no. 5, pp. 1028-1042, 2005.

[88] F. Rúa, S. Boussert, T. Parella et al., "Self-assembly of a cyclobutane $\beta$-tetrapeptide to form nanosized structures," Organic Letters, vol. 9, no. 18, pp. 3643-3645, 2007.

[89] L. Liu, Q. Li, S. Zhang et al., "Identification of a novel parallel $\beta$-strand conformation within molecular monolayer of amyloid peptide," Advanced Science, vol. 3, no. 6, 2016.

[90] R. Kodali and R. Wetzel, "Polymorphism in the intermediates and products of amyloid assembly," Current Opinion in Structural Biology, vol. 17, no. 1, pp. 48-57, 2007.

[91] R. Gerber, K. Voitchovsky, C. Mitchel et al., "Inter-oligomer interactions of the human prion protein are modulated by the 
polymorphism at codon 129," Journal of Molecular Biology, vol. 381, no. 1, pp. 212-220, 2008.

[92] P. Marek, A. Abedini, B. Song et al., "Aromatic interactions are not required for amyloid fibril formation by islet amyloid polypeptide but do influence the rate of fibril formation and fibril morphology," Biochemistry, vol. 46, no. 11, pp. 3255-3261, 2007.

[93] R. Harada, N. Kobayashi, J. Kim et al., "The effect of amino acid substitution in the imperfect repeat sequences of $\alpha$-synuclein on fibrillation," Biochimica et Biophysica Acta (BBA)-Molecular Basis of Disease, vol. 1792, no. 10, pp. 998-1003, 2009.

[94] R. Liu, C. McAllister, Y. Lyubchenko, and M. R. Sierks, "Residues 17-20 and 30-35 of beta-amyloid play critical roles in aggregation," Journal of Neuroscience Research, vol. 75, no. 2, pp. 162-171, 2004.

[95] W. Qi, A. Zhang, D. Patel et al., "Simultaneous monitoring of peptide aggregate distributions, structure, and kinetics using amide hydrogen exchange: application to A $\beta(1-40)$ fibrillogenesis," Biotechnology and Bioengineering, vol. 100, no. 6, pp. 12141227, 2008.

[96] J. Ryu, H.-A. Joung, M.-G. Kim, and B. P. Chan, "Surface plasmon resonance analysis of Alzheimer's $\beta$-amyloid aggregation on a solid surface: from monomers to fully-grown fibrils," Analytical Chemistry, vol. 80, no. 7, pp. 2400-2407, 2008.

[97] N. Chaudhary, S. Singh, and R. Nagaraj, "Morphology of self-assembled structures formed by short peptides from the amyloidogenic protein tau depends on the solvent in which the peptides are dissolved," Journal of Peptide Science, vol. 15, no. 10, pp. 675-684, 2009.

[98] J. D. Harper, S. S. Wong, C. M. Lieber, and P. T. Lansbury Jr., "Observation of metastable $\mathrm{A} \beta$ amyloid protofibrils by atomic force microscopy," Chemistry and Biology, vol. 4, no. 2, pp. 119125, 1997.

[99] Á. Karsai, Ü. Murvai, K. Soós, B. Penke, and M. S. Z. Kellermayer, "Oriented epitaxial growth of amyloid fibrils of the N27C mutant $\beta 25-35$ peptide," European Biophysics Journal, vol. 37, no. 7, pp. 1133-1137, 2008.

[100] H. A. Lashuel, D. M. Hartley, B. M. Petre et al., "Mixtures of wild-type and a pathogenic (E22G) form of $A \beta 40$ in vitro accumulate protofibrils, including amyloid pores," Journal of Molecular Biology, vol. 332, no. 4, pp. 795-808, 2003.

[101] K. A. Conway, S.-J. Lee, J.-C. Rochet, T. T. Ding, R. E. Williamson, and P. T. Lansbury Jr., "Acceleration of oligomerization, not fibrillization, is a shared property of both $\alpha$ synuclein mutations linked to early-onset Parkinson's disease: implications for pathogenesis and therapy," Proceedings of the National Academy of Sciences of the United States of America, vol. 97, no. 2, pp. 571-576, 2000.

[102] H. Heise, M. S. Celej, S. Becker et al., "Solid-state NMR reveals structural differences between fibrils of wild-type and diseaserelated A53T mutant $\alpha$-synuclein," Journal of Molecular Biology, vol. 380, no. 3, pp. 444-450, 2008.

[103] K. Sathasivam, A. Lane, J. Legleiter et al., "Identical oligomeric and fibrillar structures captured from the brains of R6/2 and knock-in mouse models of Huntington's disease," Human Molecular Genetics, vol. 19, no. 1, pp. 65-78, 2009.

[104] M. A. Poirier, H. Li, J. Macosko, S. Cai, M. Amzel, and C. A. Ross, "Huntingtin spheroids and protofibrils as precursors in polyglutamine fibrilization," Journal of Biological Chemistry, vol. 277, no. 43, pp. 41032-41037, 2002.

[105] G. Lodderstedt, S. Hess, G. Hause, T. Scheuermann, T. Scheibel, and E. Schwarz, "Effect of oculopharyngeal muscular dystrophy-associated extension of seven alanines on the fibrillation properties of the N-terminal domain of PABPN1," The FEBS Journal, vol. 274, no. 2, pp. 346-355, 2007.

[106] N. M. Kad, N. H. Thomson, D. P. Smith, D. A. Smith, and S. E. Radford, " $\beta 2$-microglobulin and its deamidated variant, N17D form amyloid fibrils with a range of morphologies in vitro," Journal of Molecular Biology, vol. 313, no. 3, pp. 559-571, 2001.

[107] J. D. Green, L. Kreplak, C. Goldsbury et al., "Atomic force microscopy reveals defects within mica supported lipid bilayers induced by the amyloidogenic human amylin peptide," Journal of Molecular Biology, vol. 342, no. 3, pp. 877-887, 2004.

[108] Q. Li, L. Liu, S. Zhang et al., "Modulating a $\beta 33-42$ peptide assembly by graphene oxide," Chemistry-A European Journal, vol. 20, no. 24, pp. 7236-7240, 2014.

[109] M. Anderson, O. V. Bocharova, N. Makarava, L. Breydo, V. V. Salnikov, and I. V. Baskakov, "Polymorphism and ultrastructural organization of prion protein amyloid fibrils: an insight from high resolution atomic force microscopy," Journal of Molecular Biology, vol. 358, no. 2, pp. 580-596, 2006.

[110] J. D. Green, C. Goldsbury, J. Kistler, G. J. S. Cooper, and U. Aebi, "Human amylin oligomer growth and fibril elongation define two distinct phases in amyloid formation," The Journal of Biological Chemistry, vol. 279, no. 13, pp. 12206-12212, 2004.

[111] H. K. L. Blackley, G. H. W. Sanders, M. C. Davies, C. J. Roberts, S. J. B. Tendler, and M. J. Wilkinson, "In-situ atomic force microscopy study of $\beta$-amyloid fibrillization," Journal of Molecular Biology, vol. 298, no. 5, pp. 833-840, 2000.

[112] C. S. Goldsbury, G. J. S. Cooper, K. N. Goldie et al., "Polymorphic fibrillar assembly of human amylin," Journal of Structural Biology, vol. 119, no. 1, pp. 17-27, 1997.

[113] C. S. Goldsbury, S. Wirtz, S. A. Müller et al., "Studies on the in vitro assembly of $\mathrm{A} \beta$ 1-40: implications for the search for $\mathrm{A} \beta$ fibril formation inhibitors," Journal of Structural Biology, vol. 130, no. 2-3, pp. 217-231, 2000.

[114] R. H. Pires, Á. Karsai, M. J. Saraiva, A. M. Damas, and M. S. Z. Kellermayer, "Distinct annular oligomers captured along the assembly and disassembly pathways of transthyretin amyloid protofibrils," PLoS ONE, vol. 7, no. 9, Article ID e44992, 2012.

[115] Y. Han, C. He, M. Cao, X. Huango, Y. Wang, and Z. Li, "Facile disassembly of amyloid fibrils using gemini surfactant micelles," Langmuir, vol. 26, no. 3, pp. 1583-1587, 2010.

[116] M. O. Chaney, W. B. Stine, T. A. Kokjohn et al., "RAGE and amyloid beta interactions: atomic force microscopy and molecular modeling," Biochimica et Biophysica Acta-Molecular Basis of Disease, vol. 1741, no. 1-2, pp. 199-205, 2005.

[117] M. Dong, M. B. Hovgaard, W. Mamdouh, S. Xu, D. E. Otzen, and F. Besenbacher, "AFM-based force spectroscopy measurements of mature amyloid fibrils of the peptide glucagon," Nanotechnology, vol. 19, no. 38, Article ID 384013, 2008.

[118] L. Pazzagli, C. Zoppi, L. Carresi et al., "Characterization of ordered aggregates of cerato-platanin and their involvement in fungus-host interactions," Biochimica et Biophysica Acta (BBA)-General Subjects, vol. 1790, no. 10, pp. 1334-1344, 2009.

[119] M. Kanapathipillai, S. H. Ku, K. Girigoswami, and C. B. Park, "Small stress molecules inhibit aggregation and neurotoxicity of prion peptide 106-126," Biochemical and Biophysical Research Communications, vol. 365, no. 4, pp. 808-813, 2008.

[120] I. Cardoso, C. S. Goldsbury, S. A. Müller et al., "Transthyretin fibrillogenesis entails the assembly of monomers: a molecular model for in vitro assembled transthyretin amyloid-like fibrils," Journal of Molecular Biology, vol. 317, no. 5, pp. 683-695, 2002. 
[121] W. S. Gosal, I. J. Morten, E. W. Hewitt, D. A. Smith, N. H. Thomson, and S. E. Radford, "Competing pathways determine fibril morphology in the self-assembly of $\beta 2$-microglobulin into amyloid," Journal of Molecular Biology, vol. 351, no. 4, pp. 850864, 2005.

[122] A. S. Mostaert, C. Giordani, R. Crockett, U. Karsten, R. Schumann, and S. P. Jarvis, "Characterisation of amyloid nanostructures in the natural adhesive of unicellular subaerial algae," The Journal of Adhesion, vol. 85, no. 8, pp. 465-483, 2009.

[123] E. Rhoades and A. Gafni, "Micelle formation by a fragment of human islet amyloid polypeptide," Biophysical Journal, vol. 84, no. 5, pp. 3480-3487, 2003.

[124] C. Bortolini, N. C. Jones, S. V. Hoffmann, F. Besenbacher, and M. Dong, "The influence of the localised charge of C- and Ntermini on peptide self-assembly," Soft Matter, vol. 12, no. 2, pp. 373-377, 2015.

[125] L. Niu, L. Liu, W. Xi et al., "Synergistic inhibitory effect of peptide-organic coassemblies on amyloid aggregation," ACS Nano, vol. 10, no. 4, pp. 4143-4153, 2016.

[126] L. Liu, Y. Li, D. Xia et al., "A self-assembled nanopatch with peptide-organic multilayers and mechanical properties," Nanoscale, vol. 7, no. 6, pp. 2250-2254, 2015.

[127] A. Chiovitti, P. Heraud, T. M. Dugdale et al., "Divalent cations stabilize the aggregation of sulfated glycoproteins in the adhesive nanofibers of the biofouling diatom Toxarium undulatum," Soft Matter, vol. 4, no. 4, pp. 811-820, 2008.

[128] E. Žerovnik, M. Škarabot, K. Škerget et al., "Amyloid fibril formation by human stefin B: influence of $\mathrm{pH}$ and TFE on fibril growth and morphology," Amyloid, vol. 14, no. 3, pp. 237-247, 2007.

[129] Y. Hong, M. D. Pritzker, R. L. Legge, and P. Chen, "Effect of $\mathrm{NaCl}$ and peptide concentration on the self-assembly of an ionic-complementary peptide EAK16-II," Colloids and Surfaces B: Biointerfaces, vol. 46, no. 3, pp. 152-161, 2005.

[130] A. Keller, M. Fritzsche, Y.-P. Yu et al., "Influence of hydrophobicity on the surface-catalyzed assembly of the islet amyloid polypeptide," ACS Nano, vol. 5, no. 4, pp. 2770-2778, 2011.

[131] F. Bellezza, A. Cipiciani, M. A. Quotadamo, S. Cinelli, G. Onori, and S. Tacchi, "Structure, stability, and activity of myoglobin adsorbed onto phosphate-grafted zirconia nanoparticles," Langmuir, vol. 23, no. 26, pp. 13007-13012, 2007.

[132] S. Kumar, V. K. Ravi, and R. Swaminathan, "Suppression of lysozyme aggregation at alkaline $\mathrm{pH}$ by tri- $\mathrm{N}$-acetylchitotriose," Biochimica et Biophysica Acta (BBA)_Proteins and Proteomics, vol. 1794, no. 6, pp. 913-920, 2009.

[133] C. Bortolini, L. Liu, T. M. A. Gronewold, C. Wang, F. Besenbacher, and M. Dong, "The position of hydrophobic residues tunes peptide self-assembly," Soft Matter, vol. 10, no. 31, pp. 5656-5661, 2014.

[134] S. Jun, J. R. Gillespie, B.-K. Shin, and S. Saxena, “The second $\mathrm{Cu}(\mathrm{II})$-binding site in a proton-rich environment interferes with the aggregation of amyloid- $\beta(1-40)$ into amyloid fibrils," Biochemistry, vol. 48, no. 45, pp. 10724-10732, 2009.

[135] Á. Karsai, L. Grama, Ü. Murvai, K. Soós, B. Penke, and M. S. Z. Kellermayer, "Potassium-dependent oriented growth of amyloid $\beta 25-35$ fibrils on mica," Nanotechnology, vol. 18, no. 34, Article ID 345102, 2007.

[136] E. Kvam, B. L. Nannenga, M. S. Wang, Z. Jia, M. R. Sierks, and A. Messer, "Conformational targeting of fibrillar polyglutamine proteins in live cells escalates aggregation and cytotoxicity," PLoS ONE, vol. 4, no. 5, Article ID e5727, 2009.
[137] M. S. Z. Kellermayer, Á. Karsai, M. Benke, K. Soós, and B. Penke, "Stepwise dynamics of epitaxially growing single amyloid fibrils," Proceedings of the National Academy of Sciences of the United States of America, vol. 105, no. 1, pp. 141-144, 2008.

[138] M. Kolsofszki, Á. Karsai, K. Soós, B. Penke, and M. S. Z. Kellermayer, "Thermally-induced effects in oriented network of amyloid $\beta 25-35$ fibrils," in Colloids for Nano- and Biotechnology, Progress in Colloid and Polymer Science, vol. 135, pp. 169-173, Springer, Berlin, Germany, 2008.

[139] S. Jenko, M. Škarabot, M. Kenig et al., "Different propensity to form amyloid fibrils by two homologous proteins-human stefins A and B: searching for an explanation," Proteins: Structure, Function, and Bioinformatics, vol. 55, no. 2, pp. 417-425, 2004.

[140] B. A. Chromy, R. J. Nowak, M. P. Lambert et al., "Self-assembly of A $\beta 1-42$ into globular neurotoxins," Biochemistry, vol. 42, no. 44, pp. 12749-12760, 2003.

[141] M. Cao, Y. Han, J. Wang, and Y. Wang, "Modulation of fibrillogenesis of amyloid $\beta(1-40)$ peptide with cationic gemini surfactant," The Journal of Physical Chemistry B, vol. 111, no. 47, pp. 13436-13443, 2007.

[142] A. Parbhu, H. Lin, J. Thimm, and R. Lal, "Imaging real-time aggregation of amyloid beta protein (1-42) by atomic force microscopy," Peptides, vol. 23, no. 7, pp. 1265-1270, 2002.

[143] Y. Miura, K. Yasuda, K. Yamamoto, M. Koike, Y. Nishida, and K. Kobayashi, "Inhibition of Alzheimer amyloid aggregation with sulfate glycopolymers," in Advances in Science and Technology, Trans Tech Publications, 2009.

[144] S. Kumar, V. K. Ravi, and R. Swaminathan, "How do surfactants and DTT affect the size, dynamics, activity and growth of soluble lysozyme aggregates?" Biochemical Journal, vol. 415, no. 2, pp. 275-288, 2008.

[145] W. D. Marcus, H. Wang, S. M. Lindsay, and M. R. Sierks, “Characterization of an antibody scFv that recognizes fibrillar insulin and $\beta$-amyloid using atomic force microscopy," Nanomedicine: Nanotechnology, Biology, and Medicine, vol. 4, no. 1, pp. 1-7, 2008.

[146] L. Tang, H.-T. Li, H.-N. Du, F. Zhang, X.-F. Hu, and H.-Y. $\mathrm{Hu}$, "Study of the disassembly-assembly process of $\alpha$-synuclein fibrils by in situ atomic force microscopy," Micron, vol. 37, no. 7, pp. 675-679, 2006.

[147] D. E. Dunstan, P. Hamilton-Brown, P. Asimakis, W. Ducker, and J. Bertolini, "Shear flow promotes amyloid- $\beta$ fibrilization," Protein Engineering, Design and Selection, vol. 22, no. 12, pp. 741746, 2009.

[148] G. A. Kiselev, P. V. Kudrinskii, I. V. Yaminskii, and O. I. Vinogradova, "Studying intermolecular processes in thin surface layers with microcantilever transducers. Formation of protein fibrils on a solid support," Protection of Metals, vol. 44, no. 6, pp. 535-541, 2008.

[149] C. M. Yip, A. A. Darabie, and J. McLaurin, "A $\beta 42$-peptide assembly on lipid bilayers," Journal of Molecular Biology, vol. 318, no. 1, pp. 97-107, 2002.

[150] Ü. Murvai, J. Somkuti, L. Smeller, B. Penke, and M. S. Z. Kellermayer, "Structural and nanomechanical comparison of epitaxially and solution-grown amyloid $\beta 25-35$ fibrils," Biochimica et Biophysica Acta (BBA)_Proteins and Proteomics, vol. 1854, no. 5, pp. 327-332, 2015.

[151] Y.-P. Yu, S. Zhang, Q. Liu et al., "2D amyloid aggregation of human islet amyloid polypeptide at the solid-liquid interface," Soft Matter, vol. 8, no. 5, pp. 1616-1622, 2012. 
[152] G. Maurstad, M. Prass, L. C. Serpell, and P. Sikorski, "Dehydration stability of amyloid fibrils studied by AFM," European Biophysics Journal, vol. 38, no. 8, pp. 1135-1140, 2009.

[153] R. J. A. Hill, V. L. Sedman, S. Allen et al., "Alignment of aromatic peptide tubes in strong magnetic fields," Advanced Materials, vol. 19, no. 24, pp. 4474-4479, 2007.

[154] P. E. Marszalek, H. Li, A. F. Oberhauser, and J. M. Fernandez, "Chair-boat transitions in single polysaccharide molecules observed with force-ramp AFM," Proceedings of the National Academy of Sciences of the United States of America, vol. 99, no. 7, pp. 4278-4283, 2002.

[155] P. E. Marszalek, A. F. Oberhauser, Y.-P. Pang, and J. M. Fernandez, "Polysaccharide elasticity governed by chair-boat transitions of the glucopyranose ring," Nature, vol. 396, no. 6712, pp. 661-664, 1998.

[156] T. Fukuma, A. S. Mostaert, and S. P. Jarvis, "Explanation for the mechanical strength of amyloid fibrils," Tribology Letters, vol. 22, no. 3, pp. 233-237, 2006.

[157] A. S. Mostaert and S. P. Jarvis, "Beneficial characteristics of mechanically functional amyloid fibrils evolutionarily preserved in natural adhesives," Nanotechnology, vol. 18, no. 4, Article ID 044010, 2007.

[158] Á. Karsai, Z. Mártonfalvi, A. Nagy, L. Grama, B. Penke, and M. S. Z. Kellermayer, "Mechanical manipulation of Alzheimer's amyloid $\beta 1-42$ fibrils," Journal of Structural Biology, vol. 155, no. 2, pp. 316-326, 2006.

[159] R. M. A. Sullan, N. Gunari, A. E. Tanur et al., "Nanoscale structures and mechanics of barnacle cement," Biofouling, vol. 25, no. 3, pp. 263-275, 2009.

[160] B. L. Smith, T. E. Schäffer, M. Vlani et al., "Molecular mechanistic origin of the toughness of natural adhesives, fibres and composites," Nature, vol. 399, no. 6738, pp. 761-763, 1999.

[161] S. Guo and B. B. Akhremitchev, "Packing density and structural heterogeneity of insulin amyloid fibrils measured by AFM nanoindentation," Biomacromolecules, vol. 7, no. 5, pp. 16301636, 2006.

[162] S. Guo and B. B. Akhremitchev, "Investigation of mechanical properties of insulin crystals by atomic force microscopy," Langmuir, vol. 24, no. 3, pp. 880-887, 2008.

[163] J. Kardos, K. Yamamoto, K. Hasegawa, H. Naiki, and Y. Goto, "Direct measurement of the thermodynamic parameters of amyloid formation by isothermal titration calorimetry," The Journal of Biological Chemistry, vol. 279, no. 53, pp. 55308-55314, 2004. 

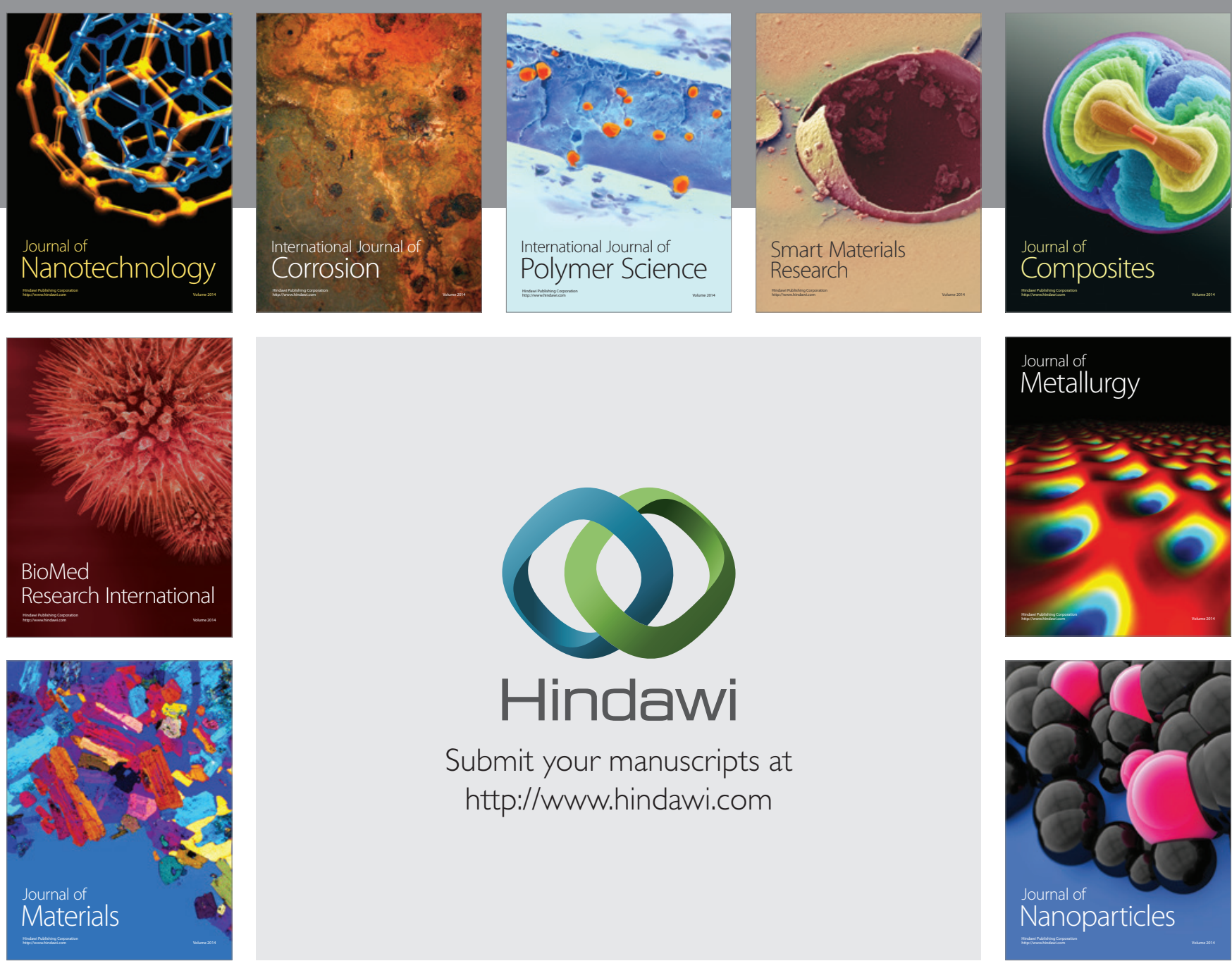

\section{Hindawi}

Submit your manuscripts at

http://www.hindawi.com

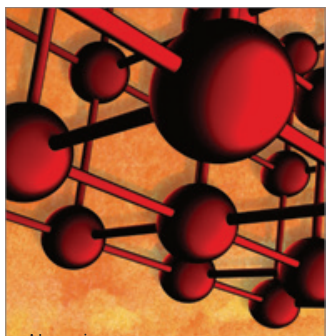

Materials Science and Engineering
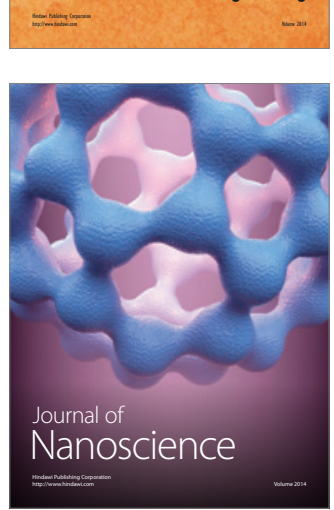
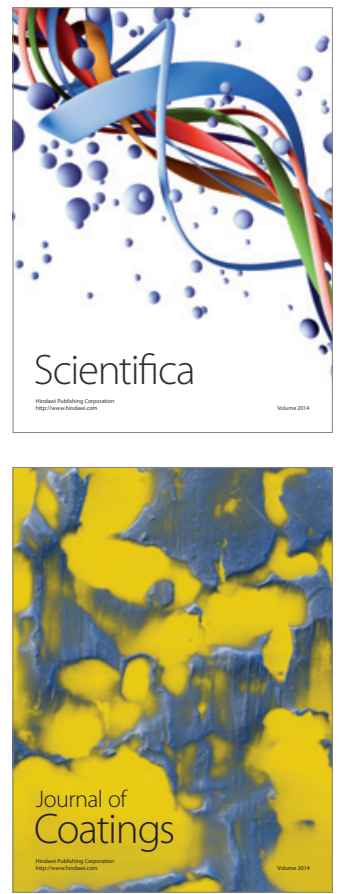
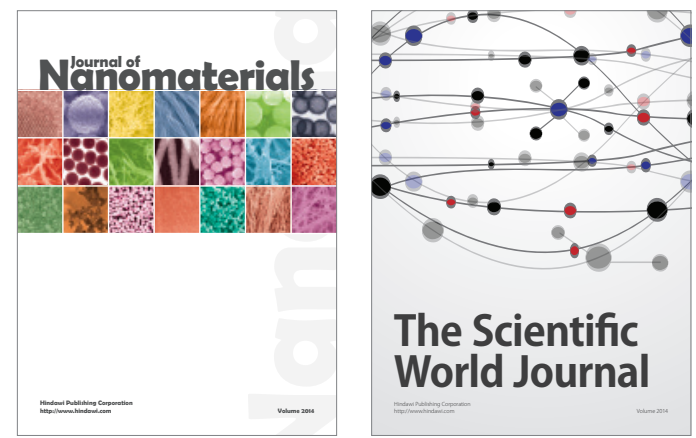

The Scientific World Journal
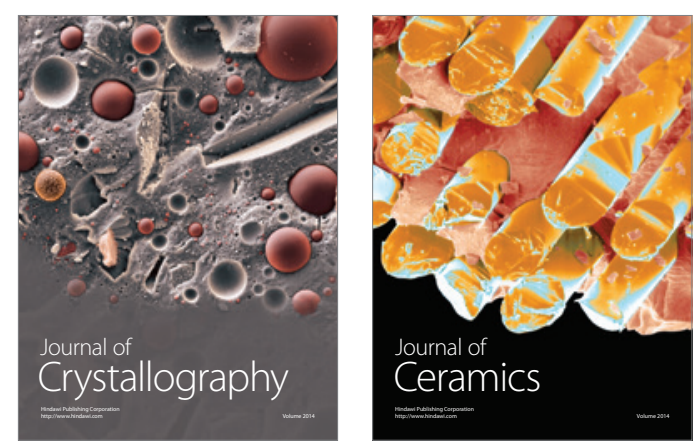
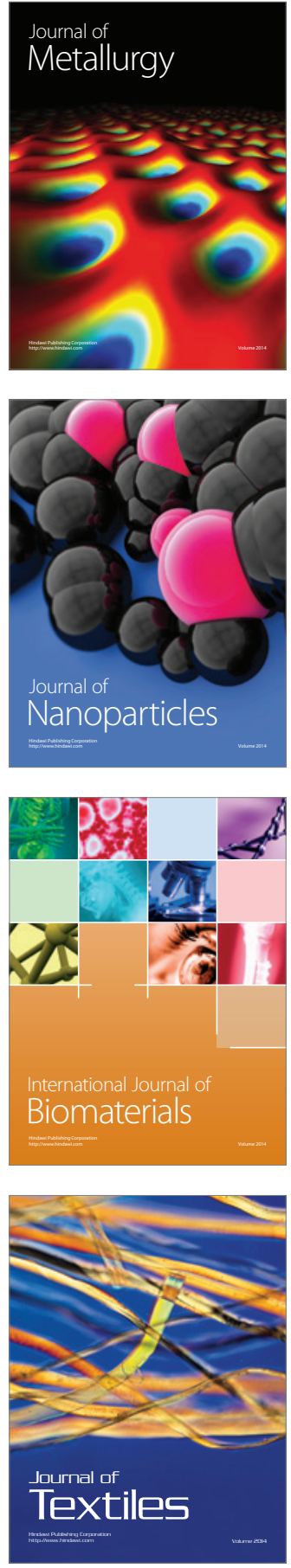